\title{
What is the benefit of ceilometers for aerosol remote sensing? An answer from EARLINET
}

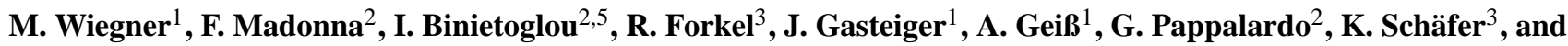 \\ W. Thomas ${ }^{4}$ \\ ${ }^{1}$ Ludwig-Maximilians-Universität (LMU), Meteorologisches Institut, Theresienstraße 37, 80333 Munich, Germany \\ ${ }^{2}$ Consiglio Nazionale delle Ricerche, Istituto di Metodologie per l'Analisi Ambientale (CNR-IMAA), C. da S. Loja - \\ Zona Industriale, 85050 Tito Scalo, Potenza, Italy \\ ${ }^{3}$ Karlsruher Institut für Technologie (KIT) - IMK-IFU, Kreuzeckbahnstraße 19, 82467 Garmisch-Partenkirchen, Germany \\ ${ }^{4}$ Deutscher Wetterdienst, Meteorological Observatory Hohenpeißenberg, Dept. Research and Development, \\ Albin-Schwaiger-Weg 10, 82383 Hohenpeißenberg, Germany \\ ${ }^{5}$ National Institute of R\&D for Optoelectronics Romania - INOE, Magurele, Romania
}

Correspondence to: M. Wiegner (m.wiegner@lmu.de)

Received: 27 February 2014 - Published in Atmos. Meas. Tech. Discuss.: 13 March 2014

Revised: 23 May 2014 - Accepted: 29 May 2014 - Published: 3 July 2014

\begin{abstract}
With the establishment of ceilometer networks by national weather services, a discussion commenced to which extent these simple backscatter lidars can be used for aerosol research. Though primarily designed for the detection of clouds it was shown that at least observations of the vertical structure of the boundary layer might be possible. However, an assessment of the potential of ceilometers for the quantitative retrieval of aerosol properties is still missing. In this paper we discuss different retrieval methods to derive the aerosol backscatter coefficient $\beta_{\mathrm{p}}$, with special focus on the calibration of the ceilometers. Different options based on forward and backward integration methods are compared with respect to their accuracy and applicability. It is shown that advanced lidar systems such as those being operated in the framework of the European Aerosol Research Lidar Network (EARLINET) are excellent tools for the calibration, and thus $\beta_{\mathrm{p}}$ retrievals based on forward integration can readily be implemented and used for real-time applications. Furthermore, we discuss uncertainties introduced by incomplete overlap, the unknown lidar ratio, and water vapor absorption. The latter is relevant for the very large number of ceilometers operating in the spectral range around $\lambda=905-910 \mathrm{~nm}$. The accuracy of the retrieved $\beta_{\mathrm{p}}$ mainly depends on the accuracy of the calibration and the long-term stability of the ceilometer. Under favorable conditions, a relative error of $\beta_{\mathrm{p}}$ on the order of $10 \%$ seems feasible. In the case of water vapor absorption,
\end{abstract}

corrections assuming a realistic water vapor distribution and laser spectrum are indispensable; otherwise errors on the order of $20 \%$ could occur. From case studies it is shown that ceilometers can be used for the reliable detection of elevated aerosol layers below $5 \mathrm{~km}$, and can contribute to the validation of chemistry transport models, e.g., the height of the boundary layer. However, the exploitation of ceilometer measurements is still in its infancy, so more studies are urgently needed to consolidate the present state of knowledge, which is based on a limited number of case studies.

\section{Introduction}

Aerosol particles are a significant constituent of the atmosphere: they influence the radiation budget directly by extinction of radiation and indirectly by modification of cloud properties, the latter also influencing the hydrological cycle (ERFaci, cloud lifetime effect and glaciation indirect effect; IPCC AR5, 2013). Moreover, air quality is affected by aerosol emissions, transport and heterogenous chemistry. As a consequence, not only is there a pure scientific interest in determining aerosol properties as a function of time and space but there is also social and economic significance. Recent examples of the dramatic impact of exceptional aerosol concentrations include the eruption of the Icelandic volcano 
Eyjafjallajökull in 2010, (e.g., Schumann et al., 2011; Wiegner et al., 2012), leading to a temporary closure of airspace, or episodes of extreme pollution from anthropogenic (e.g., in January 2013 in Beijing, China; see http://aqicn.org/map/) or natural sources (e.g., Thorsteinsson et al., 2012) with severe health risks.

As a consequence, improvements of measurement techniques and chemistry transport models are urgently needed. On the one hand, research activities are indispensable, e.g., to improve our understanding of interactions of aerosols and clouds, and to develop advanced remote sensing techniques for the assessment of optical and microphysical aerosol properties. On the other hand, infrastructures must be implemented to monitor aerosols with high spatial and temporal coverage in near-real time, e.g., ground-based networks or satellite sensors.

Lidars are undoubtedly the backbone of the measurement infrastructure as they can provide quantitative range-resolved aerosol parameters. Whereas the detection of aerosol layers and their vertical extent requires only simple singlewavelength backscatter lidars, the derivation of extinction coefficient profiles and a series of intensive aerosol properties requires advanced lidar concepts such as high-spectralresolution lidars (HSRL, Shipley et al., 1983) or Raman lidars (Ansmann et al., 1992). As a consequence of the complexity of these systems, they are quite expensive; thus their number is limited, and many of them are operated by research institutes only occasionally or during dedicated field campaigns.

By the end of the 1990s the need to upgrade lidar systems in order to better characterize aerosol particles, as well as the need for coordinated measurements to increase the density of information, had become evident. This was the main driver for establishing the "European Aerosol Research Lidar Network", EARLINET (Pappalardo et al., 2014), which is based on Raman lidars with additional spectral and polarimetric channels. From EARLINET Raman lidar data, particle backscatter $\beta_{\mathrm{p}}$ (where the subscript "p" stands for particles, and is used through the paper) and extinction coefficients $\alpha_{\mathrm{p}}$ can be retrieved independently, typically at two wavelengths (532 and $355 \mathrm{~nm})$. In the near infrared $(1064 \mathrm{~nm})$, only $\beta_{\mathrm{p}}$ can be derived. The particle linear depolarization ratio $\delta_{\mathrm{p}}$ (typically at one wavelength) is derived from many lidars providing information on the non-sphericity of the particles. Thus, together with the lidar ratio, $S_{\mathrm{p}}$, and Ångström exponents, $\kappa$, several intensive properties of aerosols are available that are very useful for the discrimination of different aerosol types ("aerosol typing”) (e.g., Groß et al., 2011, 2013; Wiegner et al., 2011). Based on this set of parameters, and under favorable conditions, it is possible to estimate aerosol microphysics, e.g., the refractive index and/or the effective radius of the particles (e.g., Müller et al., 1999). It was demonstrated for the Eyjafjallajökull plume that even the mass concentration of aerosol can be estimated if high-quality lidar and photometer data are evaluated (e.g., Gasteiger et al., 2011a); however, the uncertainty is large.

Though the potential of advanced lidars to characterize aerosol particles in detail is unsurpassed, in particular the problem of the sparse spatial sampling remains unsolved even in the case of a network such as EARLINET. The typical distance between the EARLINET stations is on the order of several hundreds of kilometers, and only a gradual increase in the number of stations is expected. Moreover, regular measurements of EARLINET are only performed on Mondays and Thursdays for a few hours; only in exceptional cases are observations performed continuously over a limited period (see Pappalardo et al., 2013). Even if more continuous observations and near-real-time data become available from EARLINET in the future, the poor spatial resolution remains an issue because it is not feasible to have advanced lidar systems "everywhere".

Since several national weather services have built up networks of ceilometers, a discussion arose regarding the potential of these instruments to solve this problem. Ceilometers are single-wavelength, eye-safe backscatter lidars. Operational and maintenance costs are quite low. They are easy to operate and data are available in near-real time. Originally, they were designed to determine cloud base heights only, but with recent improvements in hardware, several studies have attempted to retrieve information about aerosols as well.

The large number of ceilometers is a strong motivation to investigate to which extent they can fill the gaps between advanced lidar stations and how their continuous data flow can be linked to the more-or-less sparse measurements of such lidars. In this context it is relevant to identify the aerosol information that can be derived quantitatively from ceilometers. In this paper we do not discuss "technical" applications, e.g., ceilometers at runways of airports for the detection of cloud ceilings or fog.

In the following section we give a short overview over existing ceilometers, their operation and their most relevant properties. Following this, we demonstrate which optical properties can be derived from ceilometer signals from a theoretical point of view. In Sects. 5 and 6 we discuss how these properties can be derived under realistic conditions, including the aspects of calibration, water vapor absorption and vertical coverage. A brief overview over recent applications of ceilometers for aerosol research follows. Finally, ongoing and proposed activities to better exploit the benefit of ceilometers are outlined.

\section{What is a ceilometer?}

We define ceilometers as single-wavelength backscatter lidars with the following characteristics: the emitted wavelength is in the near infrared between 900 and $1100 \mathrm{~nm}$ to avoid strong Rayleigh scattering, the pulse repetition rate is on the order of a few kilohertz, and the pulse energy of the 
laser is sufficiently low to allow eye-safe operation. Typically, a time resolution of better than $1 \mathrm{~min}$ and a spatial resolution on the order of $15 \mathrm{~m}$ up to a height of $7.5 \mathrm{~km}$ or $15 \mathrm{~km}$ is available. Ceilometers can be operated continuously and unattendedly. We choose this definition as such commercially available and widespread systems will most likely be used for purposes that are beyond their original intent.

A survey of ceilometer stations has recently been performed mainly in the WMO Regional Association VI (Europe including Greenland, and areas of the Middle East). Additionally, European lidar stations as well as established lidar networks in North America (MPLnet) and Asia (ADnet) have been included. The survey (as of January 2014) now comprises about 1945 ceilometers and 144 lidar stations. The gathered information is stored in a database which contains the geographical position of the instruments together with meta-data information (institution responsible, instrument model, calibration method, data format). The data are visualized on a dedicated web page hosted by the Deutscher Wetterdienst (http://www.dwd.de/ceilomap). Embedded links guide the user to quick looks (time-height cross sections) of attenuated backscatter and range-corrected (uncalibrated) backscatter signals, as well as station web pages. Currently, quick looks are provided by about 125 stations worldwide, most of them with a time delay of a few minutes only, i.e., in near-real time. The ceilometer map and show cases for Saharan dust and volcanic ash events over Europe are available for download as Google Earth animations at the web site.

There are about 15 different instrument models in use, but most of the ceilometers are manufactured by Vaisala $(90 \%$ of all installed systems, operating at a wavelength between 905 and $910 \mathrm{~nm}$, except for the LD-40 model, which operates at $855 \mathrm{~nm})$, Jenoptik $(1064 \mathrm{~nm})$ and Eliasson $(905 \mathrm{~nm})$. A list of various ceilometers and key parameters is presented in Table 1. Pulse energy, receiver field of view, and optical design are parameters relevant for the measurement range (see Sect. 6). The main difference can be found in the optical design: the Vaisala ceilometers are monoaxial ("single lens"), whereas the Jenoptik ceilometers are biaxial.

The majority of ceilometers are operated by national meteorological and hydrological services (NMHSs) as part of national meteorological measurement programs. The primary output parameter is the cloud base height, which may be available for several cloud layers (e.g., Martucci et al., 2010). Other national ceilometer networks are operated by aviation control entities; these instruments are located close to airports. The two instrument models CT25K and CL31 (both from Vaisala) are widely used in Europe and the US (only CL31), while the Eliasson CBME80 is operated by Belgocontrol (Belgium) and the Swedish Meteorological and Hydrological Institute. The Jenoptik CHM15k is operated by the Deutscher Wetterdienst (DWD) and the UK Meteorological Office. The Jenoptik CHM15k and the Vaisala CL51 are recently developed instruments which are more powerful than the widespread CT25K or CL31 instruments. Instrumental raw data are archived by several European NMHSs and NOAA, which is essential for upcoming, more sophisticated retrievals of, for example, the aerosol backscatter coefficient. For such retrievals, however, a series of prerequisite must be fulfilled; in particular, the problem of the calibration of ceilometers must be solved.

\section{Aerosol properties from ceilometers}

The basics of lidar inversion schemes for aerosol optical properties are the same as for (high-performance) research lidars and ceilometers. They are directly linked to backscatter and extinction of radiation. This is clear from the lidar equation (1), which describes how the received signal $P$ depends on atmospheric parameters and range $z$ :

$P(z)=C_{\mathrm{L}} \frac{\beta(z)}{z^{2}} \exp \left\{-2 \int_{0}^{z} \alpha\left(z^{\prime}\right) \mathrm{d} z^{\prime}\right\}$.

System characteristics are described by $C_{\mathrm{L}}$. The backscatter coefficient $\beta$ and the extinction coefficient $\alpha$ can be split into contributions of particles and molecules, i.e.,

$\beta=\beta_{\mathrm{p}}+\beta_{\mathrm{m}}$

and

$\alpha=\alpha_{\mathrm{p}}+\alpha_{\mathrm{m}}$.

In the formulation of Eq. (1) we implicitly consider elastic backscattering and assume that only single scattering (at range $z$, in most cases equivalent to "height") occurs. The wavelength can be omitted in these equations.

The solution for the lidar equation with respect to either $\beta_{\mathrm{p}}$ or $\alpha_{\mathrm{p}}$ is well established and known as the Klett or Fernald solution (e.g., Fernald et al., 1972; Klett, 1981). Under typical atmospheric conditions the $\beta_{\mathrm{p}}$ retrieval is more accurate, in particular in cases of low aerosol concentration and/or long wavelengths, as under these conditions the retrieved $\beta_{\mathrm{p}}$ profile is less sensitive to errors of the assumed so-called lidar ratio $\left(S_{\mathrm{p}}=\alpha_{\mathrm{p}} / \beta_{\mathrm{p}}\right)$ than the $\alpha_{\mathrm{p}}$ profile.

A basic assumption of the solution is that the contributions $\alpha_{\mathrm{m}}$ and $\beta_{\mathrm{m}}$ can be calculated from air density profiles (e.g., from radiosonde ascents). The solution requires the assumption of a lidar ratio and of a boundary value at a reference height $z_{0}\left(\alpha_{\mathrm{p}}\left(z_{0}\right)\right.$ or $\left.\beta_{\mathrm{p}}\left(z_{0}\right)\right)$. The lidar ratio might be height dependent in particular if aerosol layers of different source regions are present; consequently, a reliable estimate is complicated, a problem inherent to all single-wavelength lidars. In addition, the lidar ratio at $1064 \mathrm{~nm}$ (or $905 \mathrm{~nm}$ ) cannot be determined from Raman lidars; thus one has to rely on model calculations or on coincident closure experiments. The boundary value is typically determined by means of the socalled Rayleigh calibration; that is, the boundary value is set 
Table 1. Overview over key parameters of selected ceilometers: "PRF" is pulse repetition frequency and "RFOV" the receiver field of view (half angle). Data are from user manuals of Vaisala and Jenoptik, respectively. The Jenoptik CHM15k is now known as "Nimbus". Note that the axes of the CHM15kx are tilted by $0.46 \mathrm{mrad}$.

\begin{tabular}{lccccccc}
\hline & \multicolumn{3}{c}{ Vaisala } & & \multicolumn{2}{c}{ Jenoptik } \\
\cline { 2 - 3 } \cline { 6 - 7 } & CT25k & CL31 & C51 nny & & CHM15k & CHM15kx \\
\hline Wavelength $(\mathrm{nm})$ & \multicolumn{3}{c}{$905-910$} & & \multicolumn{3}{c}{1064} \\
Optical concept & \multicolumn{3}{c}{ monoaxial (single lens) } & & \multicolumn{3}{c}{ biaxial } \\
PRF (kHz) & 5.6 & 10 & 6.5 & & $5-7$ & $5-7$ \\
Pulse energy $(\mu \mathrm{J})$ & 1.6 & 1.2 & 3 & & 8 & 8 \\
RFOV (mrad) & 0.66 & 0.83 & 0.56 & & 0.23 & 0.85 \\
\hline
\end{tabular}

to zero. This kind of calibration can only be performed if the signal-to-noise ratio (SNR) from aerosol-free regions (e.g., the upper troposphere) is sufficiently large. This might be challenging in the case of ceilometers. As a consequence, alternative approaches to determine $\beta_{\mathrm{p}}$ have been investigated. This issue is discussed in detail below.

From these general remarks we can conclude that there is only one aerosol property that might be derived quantitatively from ceilometer measurements: $\beta_{\mathrm{p}}(z)$. No other optical property can be derived: retrievals of $\alpha_{\mathrm{p}}$ and $\delta_{\mathrm{p}}$ fail because the required detection channels are missing (Raman scattering, depolarization). Consequently, the optical depth $\tau_{\mathrm{p}}$ of an aerosol layer cannot be determined. The integrated (particle) backscatter $I_{\mathrm{p}}$,

$I_{\mathrm{p}}=\int_{z_{\text {bottom }}}^{z_{\text {top }}} \beta_{\mathrm{p}}(z) \mathrm{d} z$

can only serve as a proxy for $\tau_{\mathrm{p}}$, as the lidar ratio is unknown. The retrieval of microphysical properties is clearly impossible, as no multiwavelength information is available.

According to their intended use, ceilometers were initially only exploited for cloud base determination (e.g., Eberhard, 1987; Robinson and McKay, 1989; Pal et al., 1992). The detection of clouds is easy and can be directly derived from the signal. This becomes evident when we rearrange the lidar equation:

$\frac{P(z) z^{2}}{C_{\mathrm{L}}}=\beta^{*}(z)=\beta(z) \exp \left\{-2 \int_{0}^{z} \alpha\left(z^{\prime}\right) \mathrm{d} z^{\prime}\right\}$.

Here, $\beta^{*}(z)$ is the attenuated backscatter. In the nearinfrared spectral region, the transmission term is close to unity and only gradually decreases with height. As a consequence, any pronounced change in $\beta^{*}(z)$ can be attributed to $\beta$. Moreover, as $\beta_{\mathrm{m}}$ is proportional to the air density (a monotonic function), any significant feature of the measured profile can be attributed to $\beta_{\mathrm{p}}$ as well. From Eq. (5) it is obvious that layer detection is possible from calibrated and noncalibrated signals. As a consequence, the most obvious and widely used ceilometer application with respect to aerosols is the derivation of the mixing layer height $z_{\mathrm{ml}}$ (often synonymously used with planetary boundary layer height, PBL) from the signal "shape". This information is quite useful for weather and air quality issues, but is not considered as a particle "optical property".

\section{Retrieval of the backscatter coefficient}

As mentioned above, the only optical property of aerosols that might be derived from ceilometer data is the backscatter coefficient $\beta_{\mathrm{p}}$ as a function of height (and time). To assess the benefit of ceilometers, we have to determine under which conditions it is possible to invert the lidar equation for $\beta_{\mathrm{p}}$.

\subsection{Analytical solution}

First, approaches to calibrate the ceilometer signals are discussed. As pointed out in Sect. 3 this is one prerequisite to derive $\beta_{\mathrm{p}}$ profiles. It is worthwhile to start with a few general aspects.

The result of the Klett solution with respect to $\beta_{\mathrm{p}}$ can be written as follows:

$\beta_{\mathrm{p}}(z)=\frac{Z(z)}{N(z)}-\beta_{\mathrm{m}}(z)$

with

$Z(z)=z^{2} P(z) \exp \left\{-2 \int_{0}^{z}\left[S_{\mathrm{p}}\left(z^{\prime}\right)-S_{\mathrm{m}}\right] \beta_{\mathrm{m}}\left(z^{\prime}\right) \mathrm{d} z^{\prime}\right\}$

and with $S_{\mathrm{m}}$ as the lidar ratio of air molecules. $N(z)$ can either be written in terms of the lidar constant $C_{\mathrm{L}}$ and the range integration is performed in forward direction (from the lidar),

$N(z)=C_{\mathrm{L}}-2 \int_{0}^{z} S_{\mathrm{p}}\left(z^{\prime}\right) Z\left(z^{\prime}\right) \mathrm{d} z^{\prime}$,

or in terms of a reference value $\beta_{\mathrm{p}}\left(z_{0}\right)$ and backward integration (towards the lidar), 
Table 2. Squared transmission of the overlap range $T_{\text {ovl }}^{2}$ as defined in Eq. (11) and estimate $\left(T_{\mathrm{ovl}}^{*}\right)^{2}$ derived from extrapolation (see text for details); $\tau_{\mathrm{p}}$ refers to $\lambda=1064 \mathrm{~nm}$, and $z_{\mathrm{ovl}}$ is given in kilometers.

\begin{tabular}{lllrrr}
\hline & $\tau_{\mathrm{p}}$ & $z_{\text {ovl }}$ & $T_{\text {ovl }}^{2}$ & $\left(T_{\text {ovl }}^{*}\right)^{2}$ & $\left(T_{\text {ovl }}^{*} / T_{\text {ovl }}\right)^{2}$ \\
\hline CLR & 0.028 & 0.150 & 0.995 & 0.995 & 1.0002 \\
TUR & 0.114 & 0.150 & 0.980 & 0.981 & 1.0010 \\
CLR & 0.028 & 0.600 & 0.982 & 0.985 & 1.0026 \\
TUR & 0.114 & 0.600 & 0.932 & 0.941 & 1.0106 \\
CLR & 0.028 & 1.200 & 0.968 & 0.972 & 1.0040 \\
TUR & 0.114 & 1.200 & 0.878 & 0.892 & 1.0160 \\
\hline
\end{tabular}

$N(z)=\frac{z_{0}^{2} P\left(z_{0}\right)}{\beta_{\mathrm{m}}\left(z_{0}\right)+\beta_{\mathrm{p}}\left(z_{0}\right)}+2 \int_{z}^{z_{0}} S_{\mathrm{p}}\left(z^{\prime}\right) Z\left(z^{\prime}\right) \mathrm{d} z^{\prime}$.

It was shown by Wiegner and Geiß (2012) that the lower limit of the integral in Eq. (8) can be changed from 0 to $z_{\text {ovl }}$ (i.e., the range of full overlap) when $z_{\text {ovl }}$ is small and a wavelength in the infrared is used. The accuracy of this approach strongly depends on $z_{\text {ovl }}$ and is discussed in Sect. 6.1 in more detail. The reference value in Eq. (9) is typically set to a height, $z_{0}$, where no aerosols are present.

It is common to refer to the two options as the forward and the backward approach, respectively. Which of the approaches is best for a certain data set depends on the type of the ceilometer, the meteorological situation and the availability of auxiliary data.

The forward approach is suitable for ceilometers with known $C_{\mathrm{L}}$ and long-term stability. However, ceilometers are usually delivered with proprietary software that provides a "backscatter profile" with unknown correction functions accounting for incomplete overlap and unknown scaling factors for automatic adjustments, but not $C_{\mathrm{L}}$. The backward solution, often referred to as Rayleigh calibration, is the standard approach for most research aerosol lidars at wavelengths in the UV or visible spectral range; however, this technique frequently fails in the case of ceilometers, as they are not sensitive enough to detect the molecular return.

In many cases, ancillary information is required for the forward or backward approaches, or is used to reduce uncertainties. On the one hand, this information can by provided by colocated measurements of optical radiometers (typically a sun photometer) or advanced lidar systems (Raman lidar or HSRL); on the other hand special observation setups can be exploited, e.g., horizontal measurements or cloud returns. In the case of different sampling (e.g., comparisons of day and night measurements or comparisons of columnar and rangeresolved values), the consequences for the accuracy must be carefully assessed.

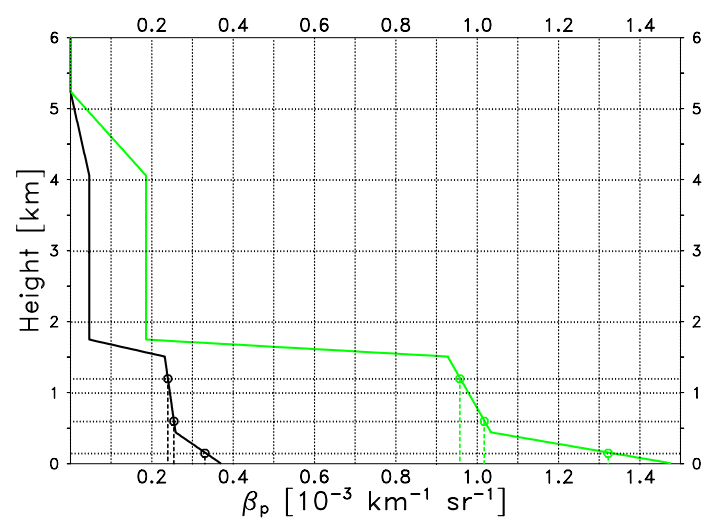

Figure 1. Profiles of aerosol backscatter coefficient $\beta_{\mathrm{p}}$ (in $10^{-3} \mathrm{~km}^{-1} \mathrm{sr}^{-1}$ ) for model calculations at $1064 \mathrm{~nm}$. The two curves indicated clear (black) and turbid (green) conditions. The dashed lines with the circles show the extrapolation to the ground for ceilometers with $z_{\mathrm{ovl}}=1.2 \mathrm{~km}, z_{\mathrm{ovl}}=0.6 \mathrm{~km}$ and $z_{\mathrm{ovl}}=$ $0.15 \mathrm{~km}$.

In the following section a short, critical review of the applicability of these approaches for ceilometer measurements is provided.

\subsection{Inversion}

\subsubsection{Forward approach}

The basic idea of this approach is simple. If the aerosol properties $\alpha_{\mathrm{p}}$ and $\beta_{\mathrm{p}}$ are known, the lidar constant $C_{\mathrm{L}}$ can be calculated from the measurement $P(z)$ according to a slightly rearranged Eq. (1), and from any $z \geq z_{\mathrm{ovl}}$ according to

$C_{\mathrm{L}}=\frac{P(z) z^{2}}{\beta(z)} \frac{1}{T_{\mathrm{ovl}}^{2}} \exp \left\{2 \int_{z_{\mathrm{ovl}}}^{z} \alpha\left(z^{\prime}\right) \mathrm{d} z^{\prime}\right\}$,

with

$T_{\text {ovl }}=\exp \left\{-\int_{0}^{z_{\text {ovl }}} \alpha\left(z^{\prime}\right) \mathrm{d} z^{\prime}\right\}$.

If the extinction coefficient and the overlap range are sufficiently small, the transmission $T_{\text {ovl }}$ (Eq. 11) is normally set to 1 ; a qualitative discussion of this statement can be found in Porter et al. (2000). For a quantitative analysis let us consider an idealized model atmosphere with a $\beta_{\mathrm{p}}$ profile at $1064 \mathrm{~nm}$ as indicated in Fig. 1. The lidar ratio is set to $S_{\mathrm{p}}=50 \mathrm{sr}$. Assuming typical conditions for Munich (central Europe) with an Ångström exponent of $\kappa=1.45$ and $\tau_{\mathrm{p}}=0.17$ at $500 \mathrm{~nm}$, we define a "clear" and "turbid" case when $\tau_{\mathrm{p}}=0.085$ and $\tau_{\mathrm{p}}=0.34$ at $500 \mathrm{~nm}$, respectively. Note that the Rayleigh contribution is very small $\left(\beta_{\mathrm{m}} \approx 8.8 \times 10^{-5} \mathrm{~km}^{-1} \mathrm{sr}^{-1}\right.$ close to the ground). For $z_{\text {ovl }}$ we select $0.15,0.6$ and $1.2 \mathrm{~km}$. In Table 2 the transmission, $T_{\text {ovl }}$, which is unknown under realistic 
conditions, is listed. An estimated transmission, $T_{\mathrm{ovl}}^{*}$,

$T_{\mathrm{ovl}}^{*}=\exp \left\{-z_{\mathrm{ovl}} \alpha_{\mathrm{p}}\left(z_{\mathrm{ovl}}\right)\right\}$

by assuming a constant $\alpha_{\mathrm{p}}=\alpha_{\mathrm{p}}\left(z_{\text {ovl }}\right)$ below $z_{\text {ovl }}$ is shown by the dashed lines in Fig. 1. The estimated $T_{\mathrm{ovl}}^{*}$ is given in the fifth column.

It can be seen for small $z_{\mathrm{ovl}}$ and $\tau_{\mathrm{p}}$ that the error contribution to the determination of $C_{\mathrm{L}}$ is indeed so small (less than $1 \%$ ) that even $T_{\text {ovl }}^{2}=1$ is acceptable. For larger extinction coefficients or larger $z_{\mathrm{ovl}}$ the error of this assumption is still below $3 \%$, but can be reduced to less than $1 \%$ if $\left(T_{\text {ovl }}^{*}\right)^{2}$ is used as an approximation of $T_{\mathrm{ovl}}^{2}$ (rightmost column). Only for ceilometers with very large $z_{\text {ovl }}($ e.g., $1.2 \mathrm{~km}$ ) and turbid conditions does the error of $C_{\mathrm{L}}$ become significant, with an underestimate of almost $13 \%$ if the transmission term is set to 1 . If, however, the unknown transmission in the overlap region is estimated by assuming a constant extinction (a common assumption), the underestimate can be reduced to less than $2 \%$. In this context it should be mentioned that for ceilometers with an overlap on the order of $1.2 \mathrm{~km}$, a correction function is typically provided (see also Sect. 6.1) that can be used for the range between approximately 0.6 and $1.2 \mathrm{~km}$. In this case the underestimate of $C_{\mathrm{L}}$ remains at $1 \%$. Though even larger $\tau_{\mathrm{p}}$ might occur, and the vertical profile of $\alpha_{\mathrm{p}}$ might deviate from the assumed decrease with height, we conclude that the accuracy of $C_{\mathrm{L}}$ is not a critical issue when a correction as described in Eq. (12) is applied.

If the system parameters of the ceilometer are constant in time or if changes can reliably be tracked, $\beta_{\mathrm{p}}$ can be derived at any time as shown by Eqs. (6) to (8). As shown above, the inherent error of $C_{\mathrm{L}}$ can be assumed to be less than $1 \%$. Additional errors are introduced by errors of $\alpha$ and $\beta$ according to Eq. (10).

Wiegner and Geiß (2012) proposed a methodology based on the provision of $\alpha_{\mathrm{p}}$ and $\beta_{\mathrm{p}}$ from the combination of selected ceilometer measurements at nighttime when Rayleigh calibration was possible (up to $2 \mathrm{~h}$ averages). Colocated sun photometer measurements of $\tau_{\mathrm{p}}$ were used to constrain $S_{\mathrm{p}}$ in the Klett algorithm. Note that it might be necessary to account for a wavelength difference between the ceilometer and the photometer. The approach was applied only when the time difference between the ceilometer and the sun photometer observations was below 2 to $3 \mathrm{~h}$ and when the variability of the aerosol distribution was low, mainly in cloud-free time periods and close to sunset or sunrise. Their algorithm was applied to Jenoptik CHM15kx measurements and accounts for intentional changes of the system's sensitivity with background radiation (i.e., changes of $C_{\mathrm{L}}$ ). From an extensive error calculation an overall uncertainty of $\beta_{\mathrm{p}}$ on the order of $10 \%$ was found for soundings of the boundary layer in $\mathrm{Mu}-$ nich, Germany, and a temporal resolution of a few minutes. Thus, data can easily be used for near-real-time applications.

An alternative methodology makes use of colocated and coincident measurements with a high-performance

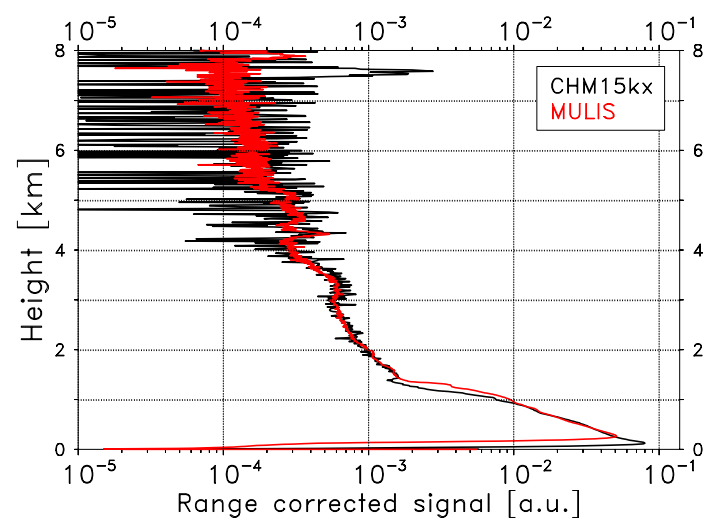

Figure 2. Comparison of $P z^{2}$ at $1064 \mathrm{~nm}$ (in arbitrary units) of the ceilometer (CHM15kx) in Munich (black) and the EARLINET lidar (MULIS) in Maisach (red), 5 May 2011, averaged from 20:00 to 20:20 UTC. The signals are normalized between 0.5 and $1.0 \mathrm{~km}$.

multiwavelength Raman lidar such as available within EARLINET was proposed by Wiegner (2010). If measurements at the same wavelength are available, the ratio of the signals (lidar and ceilometer) directly provides the ratio of the respective lidar constants $C=C_{\mathrm{L}, 1} / C_{\mathrm{L}, 2}$. Following this, the backward solution is applied to the data of the advanced lidar system. With a carefully estimated lidar ratio and Rayleigh calibration, $\alpha_{\mathrm{p}}$ and $\beta_{\mathrm{p}}$ can be determined and thus - according to Eq. (10) $-C_{\mathrm{L}, 1}$ of the advanced lidar. With the above-mentioned factor, $C$, the lidar constant of the ceilometer $C_{\mathrm{L}, 2}$ can be retrieved easily. A multiwavelength Raman lidar is advantageous because it provides $\beta_{\mathrm{p}}(z)$ at infrared wavelengths with comparatively high accuracy as the spectral behavior of the aerosol optical properties can be taken into account (Pappalardo et al., 2010) (see also Sect. 5.1). Examples from EARLINET measurements at Munich (LudwigMaximilians-Universität) show that this procedure can be applied even if the two instruments are separated by $25 \mathrm{~km}$. This is possible as the terrain around Munich is quite flat and no significant local aerosol sources exist, conditions that are certainly not valid for every location. An example of such a comparison (signals averaged over $20 \mathrm{~min}$ ) is shown in Fig. 2: the lidar and the ceilometer are located in Maisach and Munich, respectively. It is obvious that small differences in the profiles exist, though the overall agreement is excellent. As a result, the normalization factor $C$ slightly depends on the range where the two signals are matched. This additional uncertainty in the determination of lidar constant of the ceilometer can be avoided if the instruments are colocated.

The main advantage of the forward approach is that colocated and coincident reference measurements are required only for a limited number of cases: they could be from a Raman lidar, a HSRL or a sun photometer. The disadvantage is that the stability of the ceilometer must be monitored in order to account for a possible degradation of the detector or the laser. The variability of $C_{\mathrm{L}}$ can be accounted for by 
periodical recalibration. This might reveal a larger uncertainty of the applied $C_{\mathrm{L}}$ and hence reduced accuracy of the $\beta_{\mathrm{p}}$ retrieval.

In this context, we want to briefly mention a particular approach proposed by O'Connor et al. (2004). This approach relies on measuring the path-integrated $\beta^{*}(z)$ in a fully attenuating stratocumulus cloud. It was shown that the integrated $\beta^{*}(z)$ is equal to the reciprocal of twice the lidar ratio and the multiple scattering factor $\eta$ (Platt, 1979), provided that these parameters are range independent. In cases when $S_{\mathrm{p}}$ and $\eta$ of the cloud are known, the ceilometer data can be scaled until the integrated backscatter agrees with the theoretical value. As a consequence, $C_{\mathrm{L}}$ has been assessed. According to the authors, calibration within $10 \%$ relative uncertainty can be achieved.

This approach was successfully applied by Stachlewska et al. (2010) when they used returns from low-level cumulus clouds in the Arctic that did not saturate the ceilometer signals. In general, however, this approach might be challenging for ceilometers as their sensitivity is optimized for aerosol backscattering (e.g., detection of the boundary layer top) and cirrus clouds, and thus the strong return from low liquid water clouds might saturate the detector. If, furthermore, the penetration depth of the ceilometer signal is only a few range bins and the dynamical range of the signal is extremely large, the exploitation of the signal is critical. The unknown multiple-scattering factors further limit the accuracy of the calibration. Even if these problems can be solved, the procedure is excepted to be quite time consuming.

\subsubsection{Backward approach}

Ceilometers typically work in a spectral region where the molecular scattering is weak. Thus, combined with the low pulse energy of ceilometers, the detection of molecular signals is intrinsically very difficult. Thus, significant temporal averaging over time periods that depend on the SNR of the ceilometer data is a requirement for performing a Rayleigh calibration. However, the low SNR might introduce quite high statistical uncertainties of the $\beta_{\mathrm{p}}$ retrieval, and undetected spurious aerosol loading could introduce a bias.

A two-step approach based on the Rayleigh calibration was proposed by (Binietoglou et al., 2011). This inversion technique is based on the idea that the above-mentioned problem can be overcome by integrating the ceilometer signals over quite a long period, up to $8 \mathrm{~h}$. Such an integration improves the SNR, consequently allowing the detection of molecular signals at typically aerosol-free altitudes - e.g., $6 \mathrm{~km}-$ even during daytime. In the first step of the algorithm, the signals of the selected long period are averaged and a backward inversion is performed, thus obtaining a "reference" backscatter coefficient profile with a boundary value

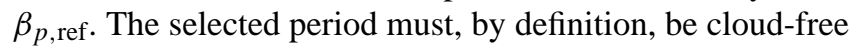
at the calibration altitude, but aerosol layers at lower altitudes do not need to be stable in time. In the second step, the Klett inversion is performed with a higher temporal resolution, using the reference profile to estimate a calibration value at a lower altitude even if aerosols are present. Binietoglou et al. (2011) compared their retrieval with $\beta_{\mathrm{p}}$ profiles derived from the multiwavelength lidar PEARL (Potenza EARLINET Raman lidar), and the agreement for the selected few cases looks promising; however, more investigations are needed.

Several authors (e.g., Heese et al., 2010; Wiegner and Geiß, 2012) have confirmed that several hours of cloud-free conditions are required for the Rayleigh calibration: for the Jenoptik CHM15kx, averages over 2 and $3 \mathrm{~h}$ are required for night- and daytime measurements, respectively. For Vaisala's CL 51 ceilometer similar conclusions hold. This is a limitation that, depending on the region, can be rather restrictive. It should be emphasized that any kind of Rayleigh calibration fails in the presence of low or mid-level clouds.

A common method used to attempt to overcome the inherent problems of the backward solution is the use of the aerosol optical depth $\tau_{\mathrm{p}}$ from colocated sun photometer measurements (see, for example, Flentje et al., 2010 or Heese et al., 2010). In this approach, the $\beta_{\mathrm{p}}$ retrieval from the ceilometer measurements must be converted into a $\alpha_{\mathrm{p}}$ profile assuming a certain lidar ratio. The two parameters required for the backward approach, $S_{\mathrm{p}}$ and $\beta_{\mathrm{p}, \text { ref }}$, can be iterated until integration of $\alpha_{\mathrm{p}}$ yields the aerosol optical depth received from the photometer. In the case of nighttime measurements, $\tau_{\mathrm{p}}$ is interpolated from the previous and/or following day. In this case, the stability of the atmospheric stratification must be confirmed by adequate measurements; inspection of timeheight cross sections of range-corrected ceilometer signals might be sufficient in most cases: in particular the advection of elevated layers (e.g., Saharan dust) can be detected by this approach. The potential of star or lunar photometers (Barretou et al., 2013) has not yet been exploited to substitute the missing sun photometer measurements at night.

To avoid assumptions of the aerosol optical depth during nighttime, Heese et al. (2010) used the wavelength independent extinction of cirrus clouds provided by coincident lidar measurements to estimate a boundary value and assumed a standard lidar ratio.

Another basic problem arises from the region of incomplete overlap of the ceilometer. With increasing height, the agreement between the optical depths suffers from the unknown $\tau_{\mathrm{p}}$ of the missing layer. To reduce this problem, ground-based measurements of extinction coefficients might help to refine $\tau_{\mathrm{p}}$ of these layers. Flentje et al. (2010) used nephelometer measurements for this purpose; consequently, additional assumptions are required to estimate extinction coefficient and to extrapolate to the ceilometer wavelength (Porter et al., 2000). If no auxiliary measurements are available, a vertically constant $\alpha_{\mathrm{p}}$ is assumed within the overlap region (cf. Eq. 12).

All of these strategies are quite time consuming and cannot easily be automated, as a special treatment of the data and an optimized combination of auxiliary data and assumptions is 
required for each measurement. Thus, in the case of ceilometers, the backward solution includes a number of serious shortcomings and limitations, all of which are based on the very low SNR at the far end of the measurement range.

\section{Discussion}

\subsection{The lidar ratio issue}

From Sect. 3 we know that knowledge of the lidar ratio is essential for solving the lidar equation. This problem is relevant for backscatter lidars and ceilometers, and wrong estimates affect ceilometers in the same way as backscatter lidars.

Though it is generally assumed that the systematic error of $\beta_{\mathrm{p}}$ is "small" when a wrong $S_{\mathrm{p}}$ is used, we want to discuss this issue again in more detail. For the forward solution the influence of $S_{\mathrm{p}}$ on the function $Z(z)$ in Eq. (7) is obvious. For $N(z)$ it is more complex as the lower limit of the integral is zero (Eq. 8). Thus, we split the integral into two terms and obtain

$N(z)=$

$C_{\mathrm{L}}-2 \int_{0}^{z_{\text {ovl }}} S_{\mathrm{p}}\left(z^{\prime}\right) Z\left(z^{\prime}\right) \mathrm{d} z^{\prime}-2 \int_{z_{\mathrm{ovl}}}^{z} S_{\mathrm{p}}\left(z^{\prime}\right) Z\left(z^{\prime}\right) \mathrm{d} z^{\prime}$.

It can be shown that this equation can be replaced in very good approximation (relative error below $0.5 \%$, and not depending on aerosol abundance) by

$N(z)=C_{\mathrm{L}}(1-F)-2 \int_{z_{\mathrm{ovl}}}^{z} S_{\mathrm{p}}\left(z^{\prime}\right) Z\left(z^{\prime}\right) \mathrm{d} z^{\prime}$,

with

$F=2 \int_{0}^{z_{\text {ovl }}} S_{\mathrm{p}}\left(z^{\prime}\right) \beta\left(z^{\prime}\right) \mathrm{d} z^{\prime}$.

The dependence of $F$, and thus also $N(z)$, on $S_{\mathrm{p}}$ can be determined in a straightforward manner. Results for the same model parameters as shown in Fig. 1 are shown in Fig. 3. Plotted is the ratio of the retrieved and the true (i.e., the model input) $\beta_{\mathrm{p}}$ for clear and turbid conditions, as well as when the lidar ratio is underestimated $\left(S_{\mathrm{p}}=40 \mathrm{sr}\right)$ or overestimated ( $S_{\mathrm{p}}=60 \mathrm{sr}$ ) by $10 \mathrm{sr}$. Solid lines refer to the forward approach and dashed lines to the backward approach. In the case of the forward approach, two lines each are plotted according to the different overlap heights $z_{\text {ovl }}$. It can be seen that the magnitude of the uncertainty introduced by wrong $S_{\mathrm{p}}$ estimates is on the same order of magnitude for the forward and backward approach but that the height dependence is different. In the lowermost part of the troposphere it is below 2 and $5 \%$ for the clear and turbid case, respectively. Larger uncertainties on the order of $10 \%$ only occur in the case of the

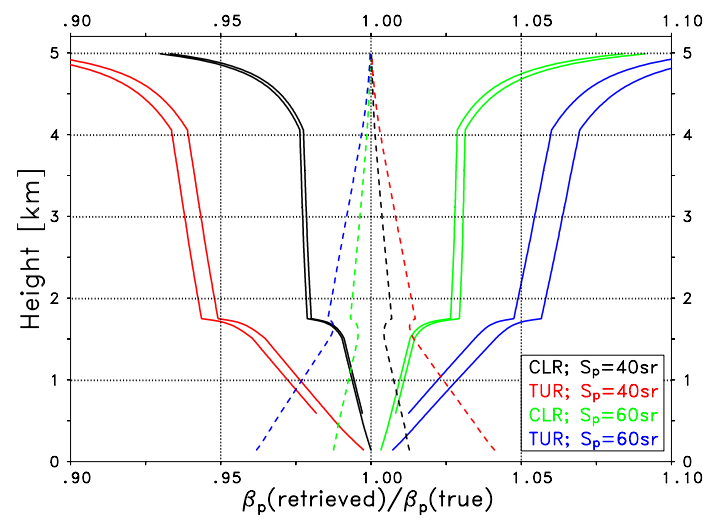

Figure 3. Ratio of the retrieved and the true $\beta_{\mathrm{p}}$ profile (see Fig. 1) when the forward (solid lines) and the backward approach (dashed lines) are applied. Retrievals for clear ("CLR") and turbid ("TUR") situations (see Table 2) and different assumptions of the lidar ratio ( $S_{\mathrm{p}}=40 \mathrm{sr}$ and $S_{\mathrm{p}}=60 \mathrm{sr}$ ) are plotted with colors according to the legend. The solid lines start either at 0.15 or $0.6 \mathrm{~km}$ according to the assumed $z_{\mathrm{ovl}}$.

forward approach around $5 \mathrm{~km}$; however, the absolute errors remain small due to the rapid decrease in $\beta_{\mathrm{p}}$ (see Fig. 1). The influence of the $z_{\text {ovl }}$ on the forward approach is comparably low and can be neglected for any practical applications.

We conclude that though the influence of a wrong $S_{\mathrm{p}^{-}}$ assumption on $\beta_{\mathrm{p}}(z)$ is typically small, the best possible estimate should be used. Direct measurements of $S_{\mathrm{p}}$ at $1064 \mathrm{~nm}$ are, however, virtually unavailable: HSRL measurements are not known to the authors of this paper, and Raman lidars only provide $S_{\mathrm{p}}$ at 532 and/or $355 \mathrm{~nm}$, and spectral extrapolation could be critical; see, for example, Gasteiger et al. (2011b). The calculations of $S_{\mathrm{p}}$ at $1064 \mathrm{~nm}$ from scattering theory is not a realistic alternative, as the required microphysical properties are normally not available. As a consequence, a set of idealized aerosol types has been defined, and $S_{\mathrm{p}}$ of the most likely aerosol type is used.

\subsection{Water vapor absorption}

As already mentioned, most Vaisala ceilometers nominally emit radiation at $905 \mathrm{~nm}$. In fact, as the laser is not temperature stabilized, the emitted wavelength varies by a few nanometers and the effective emitted spectrum typically has a width of about $3 \mathrm{~nm}$. Furthermore, differences between individual ceilometers might occur. This wavelength range is influenced by water vapor absorption, which is not the case at $1064 \mathrm{~nm}$. As a consequence, the ceilometer signal is influenced by the (highly variably) atmospheric water vapor distribution at the time of the measurement, and Eq. (3) must be replaced with

$\alpha=\alpha_{\mathrm{p}}+\alpha_{\mathrm{m}}+\alpha_{\mathrm{w}}$, 
where $\alpha_{\mathrm{w}}$ is the range dependent water vapor (volume) absorption coefficient, averaged over the respective wavelength range. To correct for the water vapor effect it is necessary to know the vertical distribution of the absolute humidity (or an equivalent quantity), the spectral absorption coefficients of water vapor and the spectrum of the laser. Typically, the latter is unknown for a given measurement. The water vapor distribution can be derived from sophisticated differential absorption lidars or Raman lidars, numerical models, or radiosonde ascents, i.e., from temperature and relative humidity profiles, often with limited accuracy and poor vertical resolution. If no radiosonde data are available, one has to rely on standard profiles and integrated values such as precipitable water, $w$, a particularly critical approach in view of the large spatiotemporal variability of water vapor.

If water vapor absorption takes place, Eq. (7) must be replaced with

$Z(z)=z^{2} P(z) \exp \left\{-2 \int_{0}^{z}\left[\left(S_{\mathrm{p}}-S_{\mathrm{m}}\right) \beta_{\mathrm{m}}-\alpha_{\mathrm{w}}\right] \mathrm{d} z^{\prime}\right\}$.

A case study of the water vapor effect on signals of Vaisala's CT25k ceilometer was presented by Markowicz et al. (2008), but under operational conditions such a detailed consideration of water vapor absorption is not possible. Sundström et al. (2009) also encountered the absorption problem when evaluating CL31 measurements. To illustrate the influence of water vapor on the ceilometer signal and the consequences for aerosol retrievals, a small numerical study may help. The aerosol distribution introduced in Sect. 4.2.1 (Fig. 1) is assumed, the water vapor distribution is described in terms of relative humidity $f$ and set to either 0 or $99 \%$ for certain height ranges, and $p$ and $T$ profiles according to the US standard atmosphere (Anderson et al., 1986) are used. To investigate the water vapor absorption effect separately, we assume that the aerosol is hydrophobic. It is assumed that the laser emits at between 903 and $907 \mathrm{~nm}$ with equal probability; absorption coefficients are calculated from a parameterization (Gasteiger et al., 2014) as part of libRadtran (Mayer and Kylling, 2005). The absorption data are based on the HITRAN spectroscopic database (Rothman et al., 2005) and the MT-CKD continuum model (Clough et al., 2005).

Figure 4 shows simulated ceilometer returns $\left(P z^{2}\right)$ for four cases with different idealized water vapor distributions. The black and red lines are for $f=99 \%$ below $0.45 \mathrm{~km}$ (case 1) and $2.0 \mathrm{~km}$ (case 2), respectively. A water vapor distribution between 0 and $2 \mathrm{~km}$ with a dry layer $(f=0 \%$ between 0.8 and $1.2 \mathrm{~km}$ ) is shown in green (case 3), whereas the blue line is for a humid layer ( $f=99 \%$ between 2.5 and $3.0 \mathrm{~km}$, case 4). These examples were selected to cover extreme cases. With respect to aerosol layer detection, it can immediately be concluded, for the turbid (not shown) and even the clear case, that the different water vapor distributions result in signal changes much smaller than could be expected at the top of the mixing layer or in the presence of

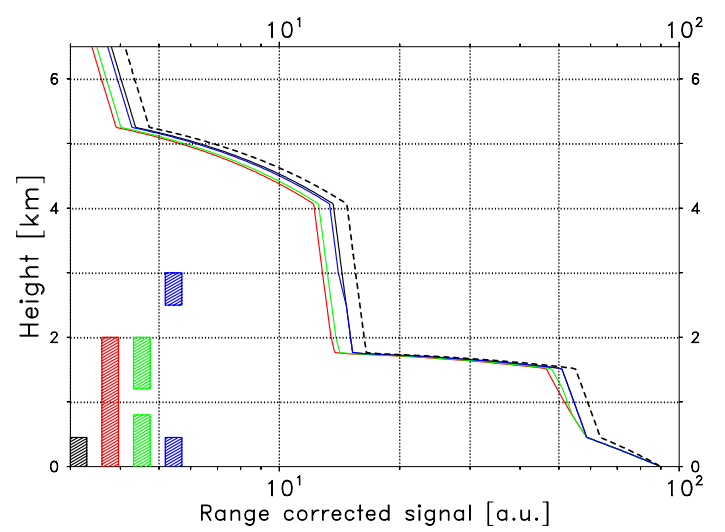

Figure 4. Simulated range-corrected ceilometer signals (in arbitrary units) at $905 \mathrm{~nm}$ influenced by different vertical water vapor distributions (cases 1 to 4 ): the relative humidity is set to $99 \%$ in height ranges as indicated by the colored bars in the left corner of the figure; elsewhere it is assumed to be $0 \%$. The dashed line is for a dry atmosphere. Like for aerosol distribution, the clear case shown in Fig. 1 is selected.

elevated aerosol layers. The reason is that aerosol backscatter, which is primarily utilized for layer detection, remains unchanged. Only in cases of a dry layer in a very humid PBL can the slope of the ceilometer signals be modified in a way that might be misinterpreted as a weak internal aerosol layer. As a consequence, it is very unlikely that water vapor absorption leads to a misinterpretation of the aerosol stratification.

However, for the retrieval of $\beta_{\mathrm{p}}(z)$ profiles, water vapor absorption plays an important role. This can be demonstrated if the ceilometer measurements as shown in Fig. 4 are inverted by the backward algorithm. Note that the forward algorithm cannot be used here as it is impossible to reliably determine the lidar constant $C_{\mathrm{L}}$ due to the unknown water vapor absorption. Figure 5 shows examples of the accuracy of the retrieval, expressed as the ratio of the retrieved and the true $\beta_{\mathrm{p}}$. Here, water vapor absorption is not taken into account; this situation is typical when ceilometer data are evaluated. The examples correspond to water vapor distribution case 3 (left, with a total water vapor content $w=14.0 \mathrm{~kg} \mathrm{~m}^{-2}$ ), and distribution case 4 (right, $w=7.3 \mathrm{~kg} \mathrm{~m}^{-2}$ ), and the clear and turbid case of the aerosol optical depth. It can be seen that, in general, the aerosol backscatter coefficient is significantly overestimated, up to $20 \%$. The reason for this is that water vapor absorption is interpreted as aerosol extinction. The deviation also depends on the selected lidar ratio $S_{\mathrm{p}}$; however, this effect is in most cases lesser than the effect due to the neglected water vapor.

Note that for spectral ranges with stronger water vapor absorption (e.g., 905-910 nm), the errors are larger, up to $35 \%$. Errors also increase if $w$ is larger, e.g., in tropical atmospheres, or if there is undetected water vapor in the Rayleigh fit range. 

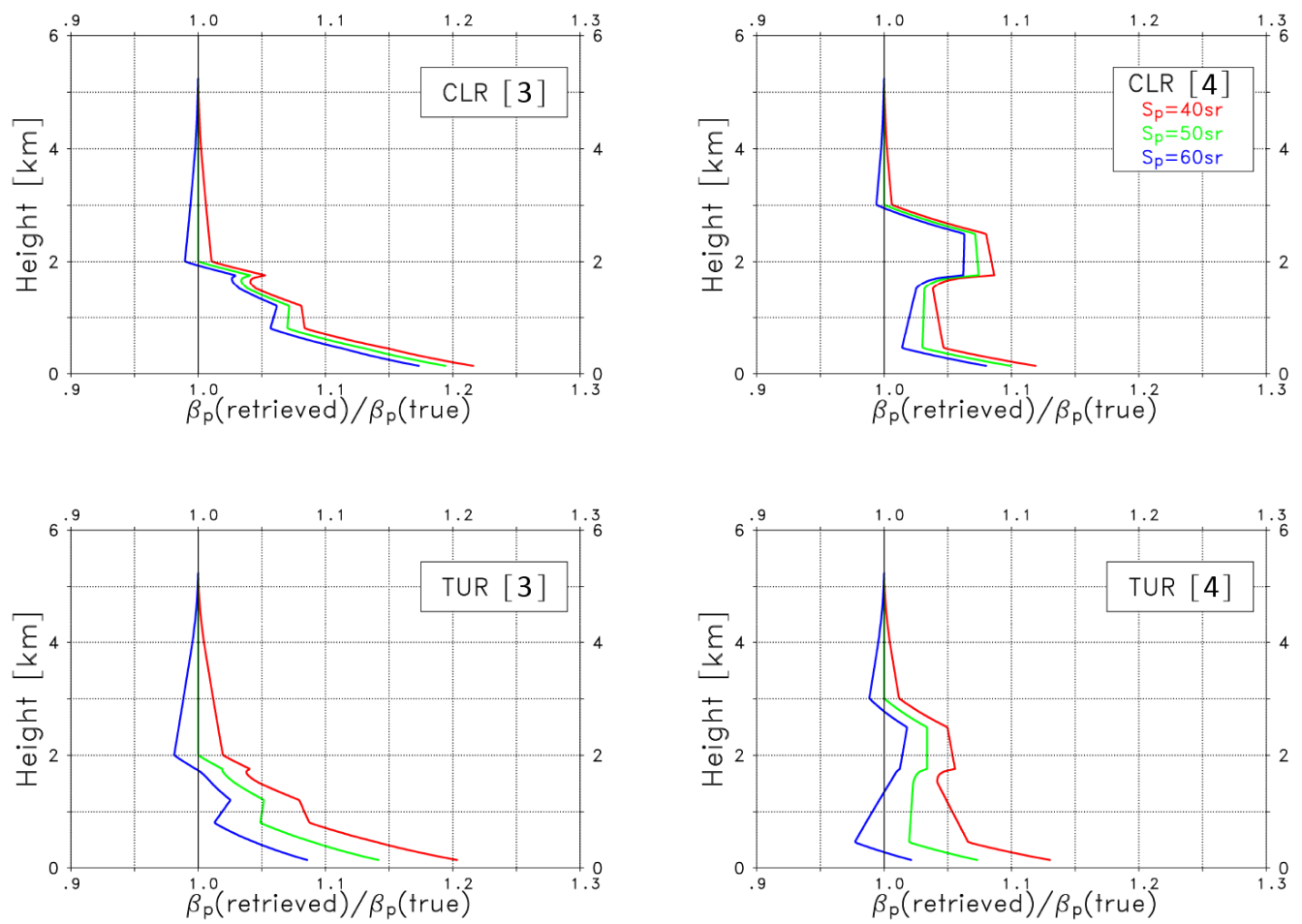

Figure 5. Ratio of retrieved (from the backward algorithm) and the true $\beta_{\mathrm{p}}$ for clear (upper row) and turbid conditions (bottom) and different water vapor distributions (case 3 on the left, case 4 on the right). The colors, indicating $S_{\mathrm{p}}$ as used in the retrievals, are given in the upper-right panel. The retrievals do not account for water vapor absorption.

As a conclusion it is mandatory to consider water vapor absorption when aerosol optical properties are to be retrieved from ceilometer measurements in the spectral region around $905 \mathrm{~nm}$. The degree to which the error can be reduced by using water vapor profiles derived from radio sonde ascents, calculated from relative humidity and temperature, can only be estimated as it depends on the temporal and spatial difference of the ceilometer measurement and the radio sonde launch, the total water vapor content, the vertical resolution of the water vapor profile, and the emitted spectrum of the laser.

For demonstration purposes, let us assume a heightindependent relative uncertainty of the absolute humidity of $20 \%$ and an effective absorption coefficient $\alpha_{\mathrm{w}}(z)$ estimated from the weighted water vapor transmission $T_{\mathrm{w}, \text { eff }}$ according to Eq. (18):

$T_{\mathrm{w}, \text { eff }}^{2}(z)=$
$\frac{\sum_{i=1}^{N} w_{i} T_{\mathrm{w}}^{2}\left(\lambda_{i}, z\right)}{\sum_{i=1}^{N} w_{i}}=\exp \left\{-2 \int_{0}^{z} \alpha_{\mathrm{w}}\left(z^{\prime}\right) \mathrm{d} z^{\prime}\right\}$.

Here, $\lambda_{i}$ is a set of $N$ representative wavelengths in the spectral range of the laser and $w_{i}$ the corresponding weights. Then, $\alpha_{\mathrm{w}}(z)$, as required for Eq. (17), can be determined and the backward algorithm used to retrieve $\beta_{\mathrm{p}}$. We have applied this approach to the first two examples of Fig. 5 (case 3 and case 4, clear) with an under- and an overestimate of $\alpha_{\mathrm{w}}$ of $20 \%$. The same uncertainty of the lidar ratios $S_{\mathrm{p}}$ as above is assumed. The results are shown in Fig. 6 in terms of the ratio of the retrieved and the correct $\beta_{\mathrm{p}}$. It can be seen that the error in $\beta_{\mathrm{p}}$ is considerably reduced compared to before to less than $5 \%$ vs. 10 and $20 \%$ (see Fig. 5).

\section{The measurement range}

The measurement range of a ceilometer is essential for various reasons. A trivial reason is that the benefit of aerosol information increases with the vertical coverage; in particular, the lowest layers of the troposphere are of interest as most of the aerosols reside there and the most direct impact on life is close to the ground. A second reason is that the better the coverage of the lowermost atmosphere, the better the fulfilment of the requirements of the inversion according to Eq. (8) (see Wiegner and Geiß (2012)). The coverage of the free troposphere is required for the Rayleigh calibration.

\subsection{The near end}

The lower limit of the measurement range is - as already demonstrated - a crucial point for the applicability of the forward approach as shown in Eq. (11), and for the 

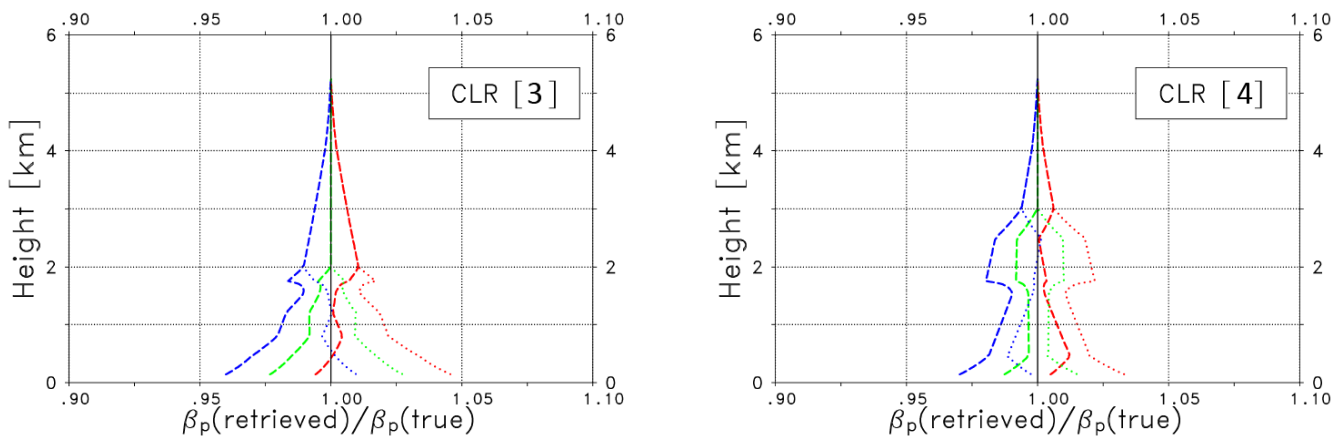

Figure 6. Ratio of retrieved and true $\beta_{\mathrm{p}}$ for clear conditions and different water vapor distributions (left: case 3; right: case 4) with an overestimate (dashed) and an underestimate (dotted) of the water vapor absorption by $20 \%$. The colors indicate $S_{\mathrm{p}}$ as used in the retrieval (50 sr green, $40 \mathrm{sr}$ red, $60 \mathrm{sr}$ blue).

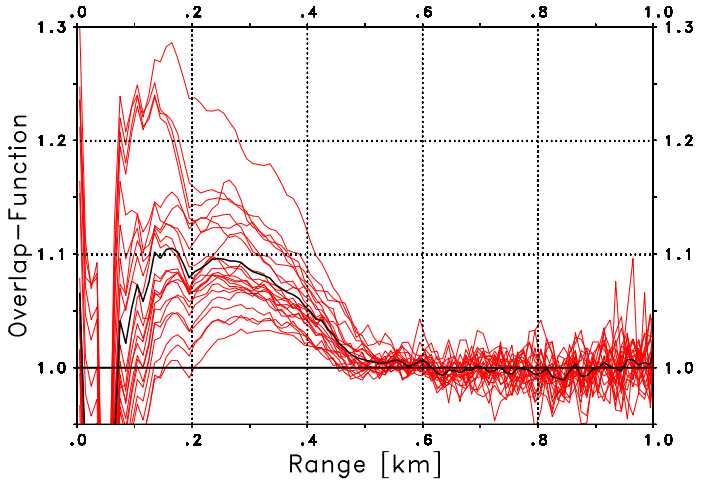

Figure 7. Overlap function $O(z)$ as determined from horizontal measurements (Vaisala CL51 ceilometer, 5 March 2013, in Garmisch-Partenkirchen, Germany). The red lines indicate $30 \mathrm{~min}$ averages, and the black line is the average of the individual lines. For details, see the text.

consequences of the uncertainty of the assumed lidar ratio (see Eq. 15).

Typically the minimum height of ceilometer-derived $\beta_{\mathrm{p}}$ profiles is between approximately $200 \mathrm{~m}$ (e.g., CHM15kx, CL51) and $1000 \mathrm{~m}$ (CHM15k). To extend the measurement range towards the ground, overlap correction functions can be applied; they are either provided by the manufacturer or must be determined by the user. In the case of the CHM15k, Jenoptik provides overlap correction functions down to approximately $500 \mathrm{~m}$. In the case of Vaisala ceilometers, the output profiles are already corrected for incomplete overlap, but the function itself is unknown to the user and cannot be modified.

Two approaches are common to determine an overlap correction function: it can be determined from horizontal measurements or from intercomparison with lidars/ceilometers of known overlap characteristics. The first option requires horizontally homogeneous conditions with respect to $\alpha$ and $\beta$ (no local aerosol sources, no isolated dynamical systems, no orographical structures) and a ceilometer that may be operated in horizontal orientation. The constant extinction coefficient $\alpha_{0}$ can be derived from the derivative of the logarithm of the range-corrected signal (Eq. 19):

$\frac{d}{\mathrm{~d} z} \ln \left(P(z) z^{2}\right)=-2 \alpha_{0}$.

Then, the "overlap function" $O(z)$ of the ceilometer can be determined as the ratio of the measured signal and the idealized signal according to the lidar equation (Eq. 1) and the constant $\alpha_{0}$. Figure 7 shows an example based on horizontal measurements of a Vaisala CL51 ceilometer on 5 March 2013 in Garmisch-Partenkirchen. Each curve represents averages over $30 \mathrm{~min}$, and the mean overlap function is shown as the black line. To ensure that only "as homogeneous as possible" atmospheric situations are considered, averages are only used if the temporal variability of $\alpha_{0}$ is below $4 \%$ between 0.3 and $0.5 \mathrm{~km}$, and below $10 \%$ between 0.5 and $1.0 \mathrm{~km}$. Then, the latter $\alpha_{0}$ is used for the full range to determine the hypothetical signal of the ceilometer without overlap effects. In spite of the large variability of the calculated $O(z)$, our findings suggest that the signal is generally overestimated between 0.06 and $0.5 \mathrm{~km}$. Below this the signals change rapidly and are not reliable. As mentioned, the data from CL51 ceilometers undergo an internal overlap correction by the vendor software. Our results suggest that this correction is overcompensating for the incomplete overlap.

It should be mentioned that the requirement of horizontal homogeneity of the atmosphere is often hard to fulfill. Measurements at the center of Munich were found to be absolutely unsuitable, and adequate situations were rare even at Garmisch-Partenkirchen. Thus, very careful selection of the measurement site and time is mandatory.

The second option requires a reference system with the same wavelength. Here, sophisticated lidars can be very useful if dedicated near-field telescopes are available or scanning of the line of sight is possible. Then, the overlap function can be derived from the signal ratio of the ceilometer and the reference system. 


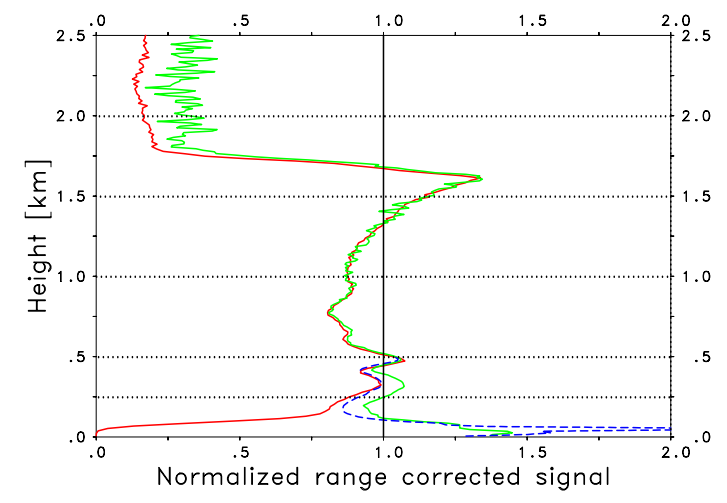

Figure 8. Range-corrected signals of a CHM15kx (red) and a CL51 ceilometer without (green) and with (blue) overlap correction as shown in Fig. 7 from 26 March 2012, averaged from 21:00 to 21:30 UTC.

In principle, ceilometers of well-known overlap characteristics might also be used as a reference. In this context, the relevance of comparing profiles at the same wavelength will be emphasized, which means that comparisons of Jenoptik and Vaisala ceilometers can be doubtful. One obvious reason is the influence of water vapor absorption (see Sect. 5.2), but even under dry conditions there are intrinsic problems. This can be demonstrated by a comparison of coincident and colocated Jenoptik CHM15kx (1064 nm) and Vaisala CL51 $(905 \mathrm{~nm})$ measurements. Figure 8 shows a comparison from 26 March 2012 in Munich; profiles are averaged over $30 \mathrm{~min}$. The signal of the Vaisala ceilometer is scaled in such a way that both range-corrected signals match between an altitude of 1.1 and $1.5 \mathrm{~km}$. It can be seen that the signals in the mixing layer are almost identical down to about $0.5 \mathrm{~km}$. If an overlap correction according to Fig. 7 is applied to the CL51 ceilometer, the agreement is extended to approximately $0.25 \mathrm{~km}$. The perfect agreement between 0.25 and $1.7 \mathrm{~km}$ not only indicates the similar performance of both ceilometers in sounding the PBL but is also an independent test of $O(z)$ as derived from horizontal measurements. Below approximately $0.2 \mathrm{~km}$, ceilometer signals should not be used.

Above the mixing layer the disagreement of the signals is primarily due to the wavelength dependence of $\beta_{\mathrm{p}}$ and the fact that the free troposphere is almost free of aerosols. Considering wavelengths at 905 and $1064 \mathrm{~nm}$ and a typical Ångström exponent of $\kappa=1.45$, the aerosol backscatter coefficient is expected to be approximately $30 \%$ larger at the shorter wavelength. Thus, if the signals are matched above the mixing layer, no overlap function $O(z)$ can be derived because the ratio of the signals predominantly depends on aerosol properties and not on the optical design.
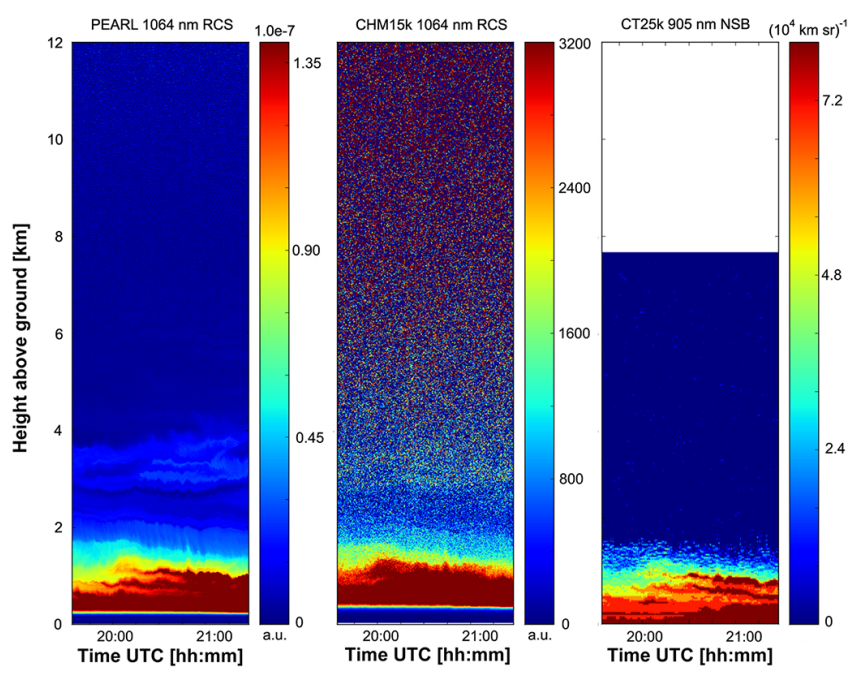

Figure 9. Observation time series obtained with PEARL (left), CHM15k (center) and CT25K (right) of 12 July 2010 from 19:15 to 21:15 UTC: shown are range-corrected signals (PEARL, CHM15k) and "normalized sensitivity backscattering" (CT25k).

\subsection{The far end}

The far end of the measurement range is particularly relevant if the backward solution including the Rayleigh calibration is applied (see Sect. 4.2.2). During nighttime, and in the case of low optical depth of the boundary layer, this might be possible when integration on the order of 1 or $2 \mathrm{~h}$ is possible. In all other cases it is quite unlikely; however, general conclusions are difficult. Thus, to determine the measurement range of ceilometers, comparisons with simultaneous and colocated lidar observations are useful. A quantitative comparison of $\beta_{\mathrm{p}}$ profiles requires complex evaluation procedures that might not be possible for each of the involved instruments, so we restrict ourselves here to the comparison of raw data.

For this purpose we use observations at CNR-IMAA Atmospheric Observatory (CIAO, Potenza, Italy), where two advanced multiwavelength EARLINET lidars, a Jenoptik CHM15k and a Vaisala CT25k, are operated simultaneously and colocated (Madonna et al., 2011). Figures 9 and 10 show two examples of comparisons between PEARL and both ceilometers. Note that the measurement ranges of the CT25k and the CHM15k are different, 7.5 and $15 \mathrm{~km}$, respectively. The comparison among the three instruments is based on range-corrected signals at $1064 \mathrm{~nm}$ in the case of PEARL and the CHM15k, and the so-called "normalized sensitivity backscattering" (NSB) at $905 \mathrm{~nm}$, the standard product of the Vaisala ceilometer. This quantity is given in units of $\mathrm{m}^{-1} \mathrm{sr}^{-1}$, which means that an internal calibration of the signals must have been applied. As its accuracy and its applicability is unknown, we treat NSB as relative numbers only. 

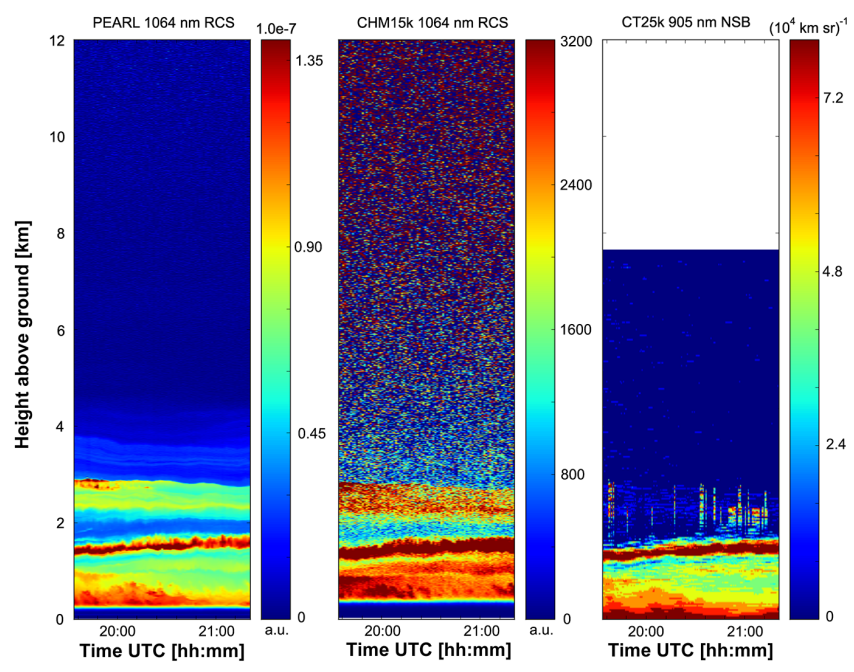

Figure 10. Same as Fig. 9 but for 25 April 2010 from 19:36 to 21:15 UTC.

The first example is shown in Fig. 9: nighttime observations of PEARL, CHM15k and CT25K of 12 July 2010 from 19:15 to 21:15 UTC are plotted. Visual inspection shows that all systems are able to detect the aerosol in the residual layer below about $2.0 \mathrm{~km}$. However, the faint aerosol layer between 3 and $4 \mathrm{~km}$, clearly observed by PEARL, is only detected by one of the ceilometers (CHM15k), with a reduced SNR as expected. The optical depth of this layer was indeed low with $\tau_{\mathrm{p}}=0.02$ at $355 \mathrm{~nm}$ as retrieved from the Raman channel of PEARL. This comparison demonstrates the lower performance of the CT25K compared to the CHM15k; reasons are most certainly the water vapor absorption affecting the CT25k at its working wavelength (see Sect. 5.2) and the lower pulse energy (Table 1). The second example (Fig. 10) refers to nighttime measurements on 25 April 2010 (19:30 to 21:15 UTC), when the particles from the eruption of Eyjafjallajökull were spread over Europe (Pappalardo et al., 2013). In this example, four distinct aerosol structures can be identified from the lidar measurements: the residual layer below about $1.0 \mathrm{~km}$, a thin but sharp layer at about $1.5 \mathrm{~km}$, an extended layer between $2.2 \mathrm{~km}$ and $2.9 \mathrm{~km}$, and a weak layer above $3.2 \mathrm{~km}$. This uppermost layer is not detected by any of the ceilometers. The extended layer, with $\tau_{\mathrm{p}}=0.15$ at $355 \mathrm{~nm}$ as derived from Raman measurements, is clearly visible in the CHM15k signals, whereas only traces can be detected by the CT25k due to the strong attenuation of the lower atmosphere. Thus, elevated aerosol layers might be completely or partly missed by CT25k measurements.

Limitations of the measurement range of the ceilometers also play a role in the detection of cirrus clouds. Again, one example may illustrate the performance (Fig. 11): here we compare the Jenoptik CHM15kx and the Vaisala CL51 ceilometer; observations are from 18 January 2012 and took place in Munich. It can be seen that extended ice clouds are
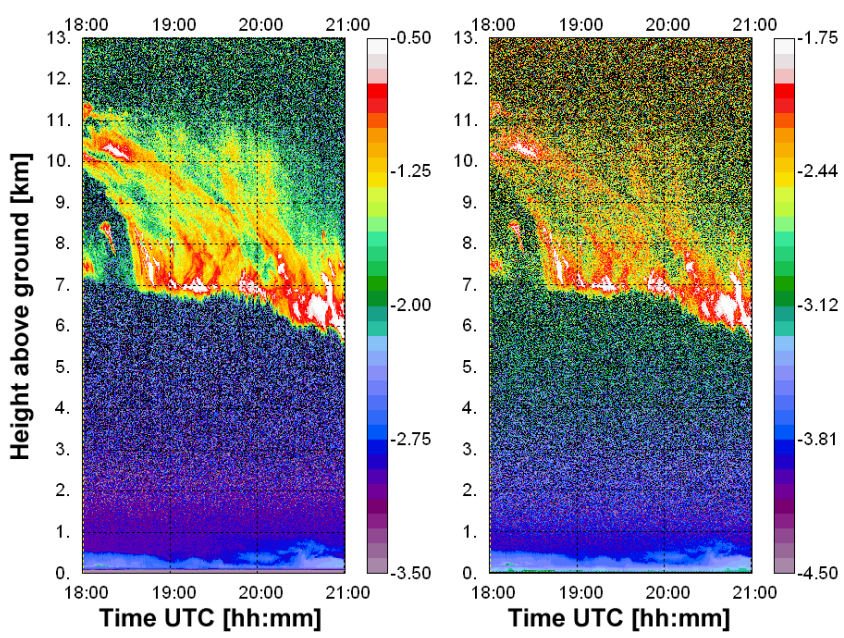

Figure 11. Range-corrected signal from 18 January 2012, 18:00 to 21:00 UTC, of Jenoptik CHM15kx (left) and Vaisala CL51 (right) at Munich; logarithmic color scale in arbitrary units.

resolved in a similar way by both ceilometers, with slightly better performance by the CHM15kx in the uppermost parts of the cloud. This is plausible in view of the different pulse energies of the ceilometers (see Table 1) and potentially larger transmission at $1064 \mathrm{~nm}$, as previously mentioned.

\section{Applications}

It has been shown in the previous sections that the derivation of optical properties of aerosols is restricted to the particle backscatter coefficient $\beta_{\mathrm{p}}$. As already mentioned, ceilometer data are, however, of use even in cases where no quantitative evaluation of optical properties is possible (e.g., Emeis et al., 2007). A few examples are briefly discussed in the following.

\subsection{Aerosol layer detection}

Aerosol layer presence and extension can be determined from uncalibrated ceilometer data; for example, in many cases it is sufficient to analyze the range-corrected signal or $\beta^{*}(z, t)$. As the top of the mixing layer $z_{\mathrm{ml}}$ is correlated with a (significant) reduction of backscattering, most algorithms are based on the investigation of the signal slope. Different algorithms are known from the literature (e.g., Melfi et al., 1985; Menut et al., 1999; Davis et al., 2000; Brooks, 2003). Elevated layers can be identified in a similar way. This has primarily been demonstrated for lidar measurements (e.g., Morille et al. (2007) or Baars et al. (2008)); however, the underlying concepts can be applied for ceilometer data as well. As a consequence, $z_{\mathrm{ml}}$ is included in the output data sets of most commercial ceilometers. However, details of the algorithms are not published; in particular, the treatment of signals that suffer from incomplete overlap remains unclear, and typically no adjustments can be made by the user. 


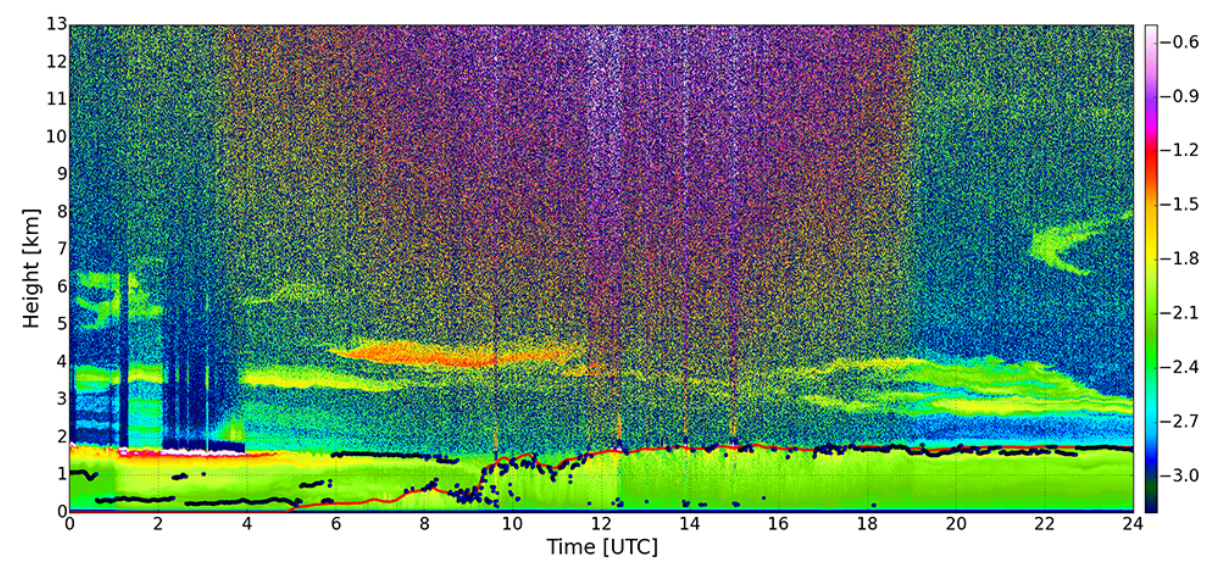

Figure 12. Time-height cross section of the range-corrected signal (logarithmic color scale in arbitrary units) of a CHM15kx ceilometer (12 July 2013, Munich, $\lambda=1064 \mathrm{~nm}$ ). The height of the mixing layer $z_{\mathrm{ml}}$ as derived from STRAT (blue) and the hybrid algorithm (red) is indicated. Time is given in UTC, and height is above ground.

An example of retrieved $z_{\mathrm{ml}}$ is shown in Fig. 12, based on CHM15kx data of 12 July 2013 at Munich. Two methods are compared: the blue line marks the results from the STRAT ("Structure of the Atmosphere") algorithm (Morille et al., 2007), and the red line is based on a hybrid algorithm that primarily aims at the determination of the convective boundary layer. The latter is a combination of methods for edge detection (e.g., wavelet covariance transform, gradient method, variance method) and edge tracking to increase the reliability of the layer detection and attribution. It is obvious that both retrievals in general show very good agreement with what is expected from visual inspection; note that normally the visual impression is taken as a reference because the "truth" is unknown. However, the example also reveals the inherent problems of these retrievals: layers are often well identified, but the attribution to atmospheric features is difficult in itself and not unambiguous. Between 07:00 and 10:00 UTC, the STRAT result "jumps" between the convective boundary layer and the residual layer. During nighttime the mixing layer shows several internal layers that sometimes lead to problems in the attribution (before 06:00 UTC).

To assess the aerosol profiling capabilities of the CHM15k ceilometer in a more general sense, we use observations from the MUSA (MUltiwavelength System for Aerosol) lidar during 2010 at CIAO as a reference, and calculate the percentage of elevated layers that were also detected by the CHM15k. The numbers were determined for day- and nighttime separately, and derived from visual inspection of time-height cross sections of $P z^{2}$. Figure 13 shows that the percentage of detection gradually decrease from $100 \%$ for layers below $1.5 \mathrm{~km}$, to $50 \%$ for layers below $3.7 \mathrm{~km}$, and to zero at about $5 \mathrm{~km}$ if nighttime measurements are considered. During daytime, when separated layers are higher in altitude due to the larger extent of the mixing layer, the percentage of detection is lower than $50 \%$ at $1.8 \mathrm{~km}$, and drops to zero for layers above approximately $3.5 \mathrm{~km}$. Though it is clear that

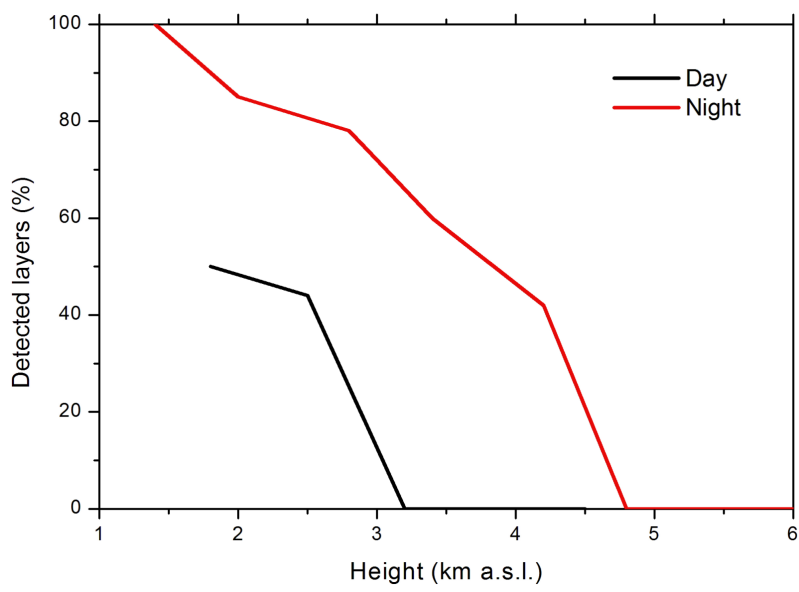

Figure 13. Percentage of elevated layers detected by the CHM15k under daytime and nighttime conditions. The EARLINET lidar MUSA is used as a reference for the total number of aerosol layers. Measurements took place at CIAO Observatory (Potenza, Italy) in 2010. Height above sea level is given.

the detection of an elevated layer depends not only on the optical depth of that layer but also on the transmission below (Mona et al., 2009), this comparison shows that ceilometers can certainly contribute useful data to climatologies of $z_{\mathrm{ml}}$ and statistics of the occurrence of elevated layers, though within certain limits.

It should be briefly mentioned that automated schemes are provided for cloud detection, typically based on the ratio of the signal and the standard deviation of the signal at the far end, as well as the exceedance of empirical thresholds.

\subsection{Validation of chemistry transport models}

In the previous section it was demonstrated that mixing layer heights in particular can be determined from ceilometer data. 


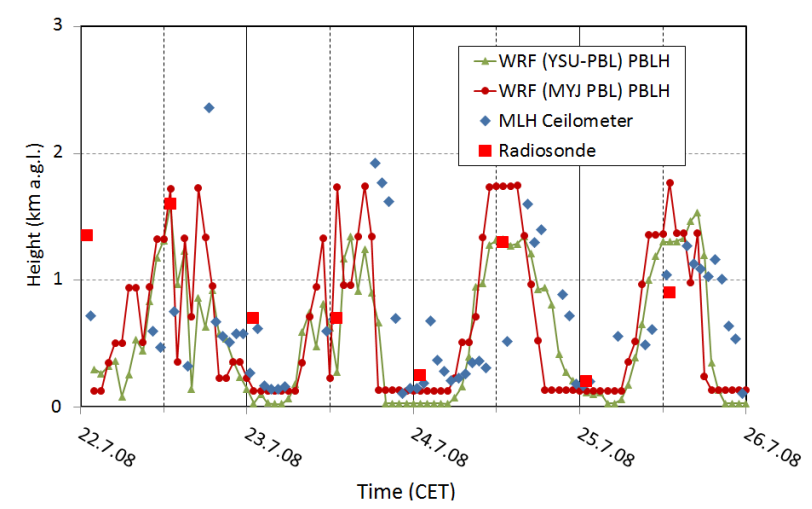

Figure 14. Comparison of PBL heights derived from WRF/Chem simulations applying PBL schemes as indicated and from ceilometer data in Augsburg for the period of 22 to 25 July 2008. The red squares indicate the mixing layer heights derived from radiosonde ascents at Oberschleißheim, Germany.

This outcome can, for example, be used for the validation of different convection parameterizations in chemistry transport models; the need became obvious, for example, with the second GABLS experiment (Svensson et al., 2011). The following simulations were carried out with WRF/Chem (Grell et al., 2005) for three nested domains with horizontal resolutions of 36,9 and $2.25 \mathrm{~km}$ and 34 layers in the vertical between the surface and the model top, which is at about $19 \mathrm{~km}$. The depth of the layers increases from approximately $30 \mathrm{~m}$ of the lowest layer to $1 \mathrm{~km}$ of the uppermost layer. Between 500 and $1000 \mathrm{~m}$ above ground, the layer depth increases from 150 to $250 \mathrm{~m}$. Two different parameterizations are compared: the YSU (Yonsei University) PBL scheme (Hong et al., 2006) and the Mellor-Yamada-Janjic (MYJ) scheme (Janjic, 2002). The YSU scheme is a first-order K-closure scheme with an additional parameterized countergradient term in the eddy-diffusion equation for considering non-local transport. For daytime convective boundary layers, the criterion for the boundary layer height is that the virtual potential temperature $\Theta_{\mathrm{v}}$ is $1 \mathrm{~K}$ larger than $\Theta_{\mathrm{v}}$ of the lowest layer. The criterion for the stable PBL is based on the bulk Richardson number $R i$ of the lowermost layer. The PBL height is the height at which $R i$ exceeds the critical Richardson number, which is assumed to have a value of 0.25 in WRF version 3 (Hong and Kim, 2008). The MYJ scheme uses the 1.5-order (level 2.5) turbulence closure model of Mellor and Yamada (1982). This scheme solves among others the equation for the turbulent kinetic energy (TKE). The PBL height is diagnosed as the height at which the TKE drops below $0.1 \mathrm{~m}^{2} \mathrm{~s}^{-2}$.

For comparison, the PBL height as determined from CL31 ceilometer measurements applying the software provided by the manufacturer is used (Münkel, 2007). Shown are measurements in downtown Augsburg, Germany, of four consecutive days of July 2008 (Fig. 14). There is no consistent picture of the agreement between observations and model, but in general the diurnal cycles and the absolute values agree fairly. The agreement is only worse for $22 \mathrm{July}$; that is, the diurnal cycle is not detected by the ceilometer retrieval and $z_{\mathrm{ml}}$ is much lower. Furthermore, a small temporal offset between measurements and model results exists. During nighttime the MYJ scheme better agrees with the ceilometer analysis than the YSU scheme. Note that the reasons for the differences are not evident: shortcomings of the model as well as misinterpretation of ceilometer signals with respect to the PBL height as mentioned above might happen. Thus, Fig. 14 highlights the urgent need of improving layer detection algorithms to fully exploit the potential of ceilometers.

Ceilometer data have also been used to validate chemistry transport model simulations of elevated layers. A recent example is the Eyjafjallajökull eruption in April 2010. Emeis et al. (2011) demonstrate in their Fig. 14 how the DWD ceilometer network has successfully been used for the validation of the simulated arrival times of the first ash cloud (16/17 April 2010) over different parts of Germany. Furthermore, the calculated altitude and the vertical extent of the layer could be confirmed, taking into account the reduced resolution of the model. On the basis of ceilometer data, the validation is, however, restricted to the dispersion of the volcanic ash plume; more detailed information such as the optical depth or the mass concentration is not available. Under favorable conditions it should only be possible to derive the integrated backscatter $I_{\mathrm{p}}$ (Eq. 4) of aerosol layers. The validation of modeled aerosol optical depth is thus not possible with ceilometer data; $I_{\mathrm{p}}$ can, however, be used as a test for plausibility.

It is certainly worthwhile extending such studies to dust transport forecasts as provided in the framework of the WMO Sand and Dust Storm Warning Advisory and Assessment System (SDS-WAS), e.g., the vertical distribution of dust as operationally provided by the DREAM model (Nickovic et al., 2001). Such applications are a strong motivation to develop ceilometers with a depolarization channel because it will be possible to distinguish dust aerosols from other types.

\section{Summary and conclusions}

Significant progress in range-resolved aerosol characterization is accomplished by means of lidar technology. However, costs for investment and maintenance of advanced lidar systems are prohibitive for establishing dense networks. As a consequence, it is worthwhile investigating to which extent the recently established ceilometer networks can contribute to aerosol remote sensing.

It was shown in this paper that the retrieval of the aerosol backscatter coefficient $\beta_{\mathrm{p}}$ from ceilometer measurements is possible; however, a careful calibration is required. A promising strategy is the application of the forward algorithm. The main advantage is that - in contrast to the backward inversion - calibration is required only occasionally and 
it is not affected by the (very) low SNR in the upper troposphere. It was emphasized that the retrieval of aerosol properties are prone to considerable errors if the ceilometer operates at wavelength sensitive to water vapor absorption (905$910 \mathrm{~nm}$ ). Incomplete overlap is not a severe issue at typical ceilometer wavelengths; nevertheless corrections should be applied if available. The uncertainties introduced by wrong lidar ratios are also comparably small in the near IR.

We want to underline that the derivation of "advanced" products such as the mass concentration of a volcanic ash layer requires information from additional instruments and/or model calculations. Thus, statements such as "mass concentration was derived by ceilometer measurements" should be avoided. Ceilometers only provide the spatial extent of the layer and - under certain conditions $-\beta_{\mathrm{p}}$; all other information (e.g., extinction coefficients, mass-toextinction conversion factors) is based on different sources (e.g., Gasteiger et al., 2011a; Perrone et al., 2012). Consequently, the accuracy of the retrieved mass concentration primarily depends on the accuracy of parameters that are not derived from the ceilometer.

Ceilometer measurements can benefit from EARLINET lidar primarily with respect to calibration. The advantage is that strictly coincident and colocated measurements are possible, even and particularly during night, when the SNR of the ceilometer is best. Then, the lidar constant $C_{\mathrm{L}}$ of the ceilometer can be determined with the best possible accuracy. If, furthermore, water vapor absorption can be excluded (e.g., at $1064 \mathrm{~nm}$ ) the uncertainty of the retrieved $\beta_{\mathrm{p}}$ could remain below $10 \%$. A generally applicable accuracy cannot be given as it depends on the actual ceilometer type, the meteorological condition and the availability of additional measurements. Case studies show that profiles of $\beta_{\mathrm{p}}$ can be provided with a height resolution of a few tens of meters and a temporal resolution of a few minutes.

It should be emphasized that ceilometer data, even if they are not calibrated, are useful. They can provide information on the aerosol stratification, e.g., mixing layer height or the extent of elevated layers. Such information can be used to qualitatively understand air quality issues and can be used for validation of chemistry transport models.

With respect to the potential of a next generation of ceilometers, we want to underline that the implementation of a depolarization channel would be a great step forward for aerosol profiling as it will provide additional information on the type of particles. Before these advanced ceilometers become operational, extensive testing with prototypes, as performed in the DIAPASON project (http://www.diapason-life. $\mathrm{eu}$, needs to completed. If made commercially available, these instruments will strongly enhance the capabilities of validate chemistry transport models.

It is clear that ceilometer-related studies are still rare. Consequently several international projects have been initiated to exploit the benefit of ceilometers in depth and to investigate strategies of combining networks of advanced lidars and ceilometers. Worthy of mention are EUMETNET's (European Meteorological Network) E-PROFILE and the COST Action ES1303 TOPROF (Towards operational ground-based profiling with ceilometers, Doppler lidars and microwave radiometers for improving weather forecasts), which deal with the calibration of ceilometers, harmonization of data formats and retrieval algorithms, and data exchange issues. Currently, a representation of ceilometer products in BUFR format (Binary Universal Form for Data Representation) is under development. The European project ACTRIS (Aerosols, Clouds, and Trace gases Research InfraStructure network) aims (among others) at the combination of EARLINET and secondary networks of ceilometers. Similar objectives are pursued within GALION (GAW Aerosol Lidar Observation Network), which focusses on the harmonization of the existing lidar networks. Common to all activities is the aim to build up a framework for real-time applications and improvements of air quality and weather prediction by assimilation of ceilometer data.

Acknowledgements. We gratefully acknowledge the financial support for the improvement of the EARLINET infrastructure by the European Commission under grant RICA-025991. The research leading to these results has received partial funding from the European Union Seventh Framework Programme (FP7/2007-2013) under grant agreement no. 262254. INOE would like to acknowledge funding received from the European Union Seventh Framework Programme for research, technological development and demonstration under grant agreement no. 289923. Technical information of Vaisala ceilometers was provided by Christoph Münkel. Figure 11 is modified from Benjamin Schaaf.

Edited by: N. Sugimoto

\section{References}

Anderson, G. P., Clough, S. A., Kneizys, F. X., Chetwynd, J. H., and Shettle, E. P.: AFGL Atmospheric Constituent Profiles (0120 km), AFGL-TR-86-0110, Hanscom AFB, MA 01736, US.

Ansmann, A., Wandinger, U., Riebesell, M., Weitkamp, C., and Michaelis, W.: Independent measurement of extinction and backscatter profiles in cirrus clouds by using a combined Raman elastic-backscatter lidar, Appl. Optics, 31, 7113-7131, 1992.

Baars, H., Ansmann, A., Engelmann, R., and Althausen, D.: Continuous monitoring of the boundary-layer top with lidar, Atmos. Chem. Phys., 8, 7281-7296, doi:10.5194/acp-8-7281-2008, 2008.

Barreto, A., Cuevas, E., Damiri, B., Guirado, C., Berkoff, T., Berjón, A. J., Hernández, Y., Almansa, F., and Gil, M.: A new method for nocturnal aerosol measurements with a lunar photometer prototype, Atmos. Meas. Tech., 6, 585-598, doi:10.5194/amt-6-585-2013, 2013.

Binietoglou, I., Amodeo, A., D’Amico, G., Giunta, A., Madonna, F., and Pappalardo, G.: Examination of possible synergy between lidar and ceilometer for the monitoring of atmospheric aerosols, Proc. SPIE 8182, Lidar Technologies, 
Techniques, and Measurements for Atmospheric Remote Sensing VII, SPIE 8182, 818209, doi:10.1117/12.897530, 2011.

Brooks, I. M.: Finding boundary layer top: application of a wavelet covariance transform to lidar backscatter profiles, J. Atmos. Ocean. Tech., 20, 1092-1105, 2003.

Clough, S., Shephard, M., Mlawer, E., Delamere, J., Iacono, M., Cady-Pereira, K., Boukabara, S., and Brown, P.: Atmospheric radiative transfer modeling: a summary of the AER codes, J. Quant. Spectrosc. Radiat. Transfer, 91, 233-244, doi:10.1016/j.jqsrt.2004.05.058, 2005.

Davis, K. J., Gamage, N., Hagelberg, C. R., Kiemle, C., Lenschow, D. H., and Sullivan, P. P.: An objective method for deriving atmospheric structure from airborne lidar observations, J. Atmos. Ocean. Tech., 17, 1455-1468, 2000.

Eberhard, W. L.: Cloud signals from lidar and rotating beam ceilometers compared with pilot ceiling, J. Atmos. Ocean. Tech., 3, 499-512, 1987.

Emeis, S., Jahn, C., Münkel, C., Münsterer, C., and Schäfer, K.: Multiple atmospheric layering and mixing-layer height in the Inn valley observed by remote sensing, Meteorol. Z., 16, 415-424, doi:10.1127/0941-2948/2007/0203, 2007.

Emeis, S., Forkel, R., Junkermann, W., Schäfer, K., Flentje, H., Gilge, S., Fricke, W., Wiegner, M., Freudenthaler, V., Groß, S., Ries, L., Meinhardt, F., Birmili, W., Münkel, C., Obleitner, F., and Suppan, P.: Measurement and simulation of the 16/17 April 2010 Eyjafjallajökull volcanic ash layer dispersion in the northern Alpine region, Atmos. Chem. Phys., 11, 2689-2701, doi:10.5194/acp-11-2689-2011, 2011.

Fernald, F. G., Herman, B. M., and Reagan, J. A.: Determination of aerosol height distributions by lidar, J. Appl. Meteorol., 11, 482-489, 1972.

Flentje, H., Claude, H., Elste, T., Gilge, S., Köhler, U., PlassDülmer, C., Steinbrecht, W., Thomas, W., Werner, A., and Fricke, W.: The Eyjafjallajökull eruption in April 2010 - detection of volcanic plume using in-situ measurements, ozone sondes and lidar-ceilometer profiles, Atmos. Chem. Phys., 10, 10085-10092, doi:10.5194/acp-10-10085-2010, 2010.

Gasteiger, J., Groß, S., Freudenthaler, V., and Wiegner, M.: Volcanic ash from Iceland over Munich: mass concentration retrieved from ground-based remote sensing measurements, Atmos. Chem. Phys., 11, 2209-2223, doi:10.5194/acp-11-22092011, 2011a.

Gasteiger, J., Wiegner, M., Groß, S., Freudenthaler, V., Toledano, C., Tesche, M., and Kandler, K.: Modeling lidarrelevant optical properties of complex mineral dust aerosols, Tellus B, 63, 725-741, doi:10.1111/j.1600-0889.2011.00559.x, $2011 b$.

Gasteiger, J., Emde, C., Mayer, B., Buras, R., Buehler, S. A., and Lemke, O.: Representative wavelengths absorption parameterization applied to satellite channels and spectral bands, J. Quant. Spectrosc. Radiat. Transfer, accepted, 2014.

Grell, G. A., Peckham, S. E., Schmitz, R., McKeen, S. A., Frost, G., Skamarock, W. C., and Eder, B.: Fully coupled "online" chemistry within the WRF model, Atmos. Environ., 39, 6957-6975, 2005.

Groß, S., Tesche, M., Freudenthaler, V., Toledano, C., Wiegner, M., Ansmann, A., Althausen, D., and Seefeldner, M.: Characterization of Saharan dust, marine aerosols and mixtures of biomass burning aerosols and dust by means of multi-wavelength depolarization- and Raman-measurements during SAMUM-2, Tellus B, 63, 706-724, doi:10.1111/j.1600-0889.2011.00556.x, 2011.

Groß, S., Esselborn, M., Weinzierl, B., Wirth, M., Fix, A., and Petzold, A.: Aerosol classification by airborne high spectral resolution lidar observations, Atmos. Chem. Phys., 13, 2487-2505, doi:10.5194/acp-13-2487-2013, 2013.

Heese, B., Flentje, H., Althausen, D., Ansmann, A., and Frey, S.: Ceilometer lidar comparison: backscatter coefficient retrieval and signal-to-noise ratio determination, Atmos. Meas. Tech., 3, 1763-1770, doi:10.5194/amt-3-1763-2010, 2010.

Hong, S.-Y. and Kim, S.-W.: Stable boundary layer mixing in a vertical diffusion scheme, Proc. Ninth Annual WRF User's Workshop, Boulder, CO, National Center for Atmospheric Research, 3.3, available at: http://www.mmm.ucar.edu/ wrf/users/workshops/WS2008/abstracts/3-03.pdf (last access: 30 May 2014), 2008.

Hong, S.-Y., Noh, Y., and Dudhia, J.: A new vertical diffusion package with an explicit treatment of entrainment processes, Mon. Weather Rev., 134, 2318-2341, 2006.

Janjic, Z. I.: Nonsingular Implementation of the Mellor - Yamada Level 2.5 Scheme in the NCEP Mesomodel, NCEP Office Note, 437, 61 pp., 2002.

Klett, J. D.: Stable analytical inversion solution for processing lidar returns, Appl. Optics, 20, 211-220, 1981.

Madonna, F., Amodeo, A., Boselli, A., Cornacchia, C., Cuomo, V., D'Amico, G., Giunta, A., Mona, L., and Pappalardo, G.: CIAO: the CNR-IMAA advanced observatory for atmospheric research, Atmos. Meas. Tech., 4, 1191-1208, doi:10.5194/amt4-1191-2011, 2011.

Markowicz, K. M., Flatau, P. J., Kardas, A. E., Remiszewska, J., Stelmaszczyk, K., and Woeste, L.: Ceilometer retrieval of the boundary layer vertical aerosol extinction structure, J. Atmos. Ocean. Tech., 25, 928-944, 2008.

Martucci, G., Milroy, C., and O'Dowd, C. D.: Detection of cloudbase height using Jenoptik CHM15K and Vaisala CL31 ceilometers, J. Atmos. Ocean. Tech., 27, 305-318, 2010.

Mayer, B. and Kylling, A.: Technical note: The libRadtran software package for radiative transfer calculations - description and examples of use, Atmos. Chem. Phys., 5, 1855-1877, doi:10.5194/acp-5-1855-2005, 2005.

Melfi, S. H., Spinhirne, J. D., Chou, S. H., and Palm, S. P.: Lidar observation of the vertically organized convection in the planetary boundary layer over the ocean, J. Clim. Appl. Meteor., 24, 806-821, 1985.

Mellor, G. L. and Yamada, T.: Development of a turbulence closure model for geophysical fluid problems, Rev. Geophys., 20, 851875, 1982.

Menut, L., Flamant, C., Pelon, J., and Flamant, P. H.: Urban boundary-layer height determination from lidar measurements over the Paris area, Appl. Optics, 38, 945-954, 1999.

Mona, L., Pappalardo, G., Amodeo, A., D’Amico, G., Madonna, F., Boselli, A., Giunta, A., Russo, F., and Cuomo, V.: One year of CNR-IMAA multi-wavelength Raman lidar measurements in coincidence with CALIPSO overpasses: Level 1 products comparison, Atmos. Chem. Phys., 9, 7213-7228, doi:10.5194/acp-97213-2009, 2009.

Morille, Y., Haeffelin, M., Drobinski, P., and Pelon, J.: STRAT: an automated algorithm to retrieve the vertical structure of the atmo- 
sphere from single-channel lidar data, J. Atmos. Ocean. Tech., 24, 761-775, doi:10.1175/JTECH2008.1, 2007.

Müller, D., Wandinger, U., and Ansmann, A.: Microphysical particle parameters from extinction and backscatter lidar data by inversion through regularization: theory, Appl. Optics, 38, 23462357, 1999.

Münkel, C.: Mixing height determination with lidar ceilometers - results from Helsinki testbed, Meteorol. Z., 16, 451-459, doi:10.1127/0941-2948/2007/0221, 2007.

Nickovic, S., Papadopoulos, A., Kakaliagou, O., and Kallos, G.: Model for prediction of desert dust cycle in the atmosphere, J. Geophys. Res., 106, 18113-18129, 2001.

O’Connor, E. J., Illingworth, A. J., and Hogan, R. J.: A technique for autocalibration of cloud lidar, J. Atmos. Ocean. Tech., 21, 777-786, 2004

Pal, S. R., Steinbrecht, W., and Carswell, A.: Automated method for lidar determination of cloud base height and vertical extent, Appl. Optics, 31, 10, 1488-1494, 1992.

Pappalardo, G., Wandinger, U., Mona, L., Hiebsch, A., Mattis, I., Amodeo, A., Ansmann, A., Seifert, P., Linné, H., Apituley, A., Alados Arboledas, L., Balis, D., Chaikovsky, A., D’Amico, G., De Tomasi, F., Freudenthaler, V., Giannakaki, E., Giunta, A., Grigorov, I., Iarlori, M., Madonna, F., Mamouri, R. E., Nasti, L., Papayannis, A., Pietruczuk, A., Pujadas, M., Rizi, V., Rocadenbosch, F., Russo, F., Schnell, F., Spinelli, N., Wang, X., and Wiegner, M.: EARLINET correlative measurements for CALIPSO: first intercomparison results, J. Geophys. Res., 115, D00H19, doi:10.1029/2009JD012147, 2010.

Pappalardo, G., Mona, L., D’Amico, G., Wandinger, U., Adam, M., Amodeo, A., Ansmann, A., Apituley, A., Alados Arboledas, L., Balis, D., Boselli, A., Bravo-Aranda, J. A., Chaikovsky, A., Comeron, A., Cuesta, J., De Tomasi, F., Freudenthaler, V., Gausa, M., Giannakaki, E., Giehl, H., Giunta, A., Grigorov, I., Groß, S., Haeffelin, M., Hiebsch, A., Iarlori, M., Lange, D., Linné, H., Madonna, F., Mattis, I., Mamouri, R.-E., McAuliffe, M. A. P., Mitev, V., Molero, F., Navas-Guzman, F., Nicolae, D., Papayannis, A., Perrone, M. R., Pietras, C., Pietruczuk, A., Pisani, G., Preißler, J., Pujadas, M., Rizi, V., Ruth, A. A., Schmidt, J., Schnell, F., Seifert, P., Serikov, I., Sicard, M., Simeonov, V., Spinelli, N., Stebel, K., Tesche, M., Trickl, T., Wang, X., Wagner, F., Wiegner, M., and Wilson, K. M.: Four-dimensional distribution of the 2010 Eyjafjallajökull volcanic cloud over Europe observed by EARLINET, Atmos. Chem. Phys., 13, 4429-4450, doi:10.5194/acp-13-4429-2013, 2013.

Pappalardo, G., Amodeo, A., Apituley, A., Comeron, A., Freudenthaler, V., Linné, H., Ansmann, A., Bösenberg, J., D’Amico, G., Mattis, I., Mona, L., Wandinger, U., Amiridis, V., AladosArboledas, L., Nicolae, D., and Wiegner, M.: EARLINET: towards an advanced sustainable European aerosol lidar network, Atmos. Meas. Tech. Discuss., 7, 2929-2980, doi:10.5194/amtd7-2929-2014, 2014.

Perrone, M. R., De Tomasi, F., Stohl, A., and Kristiansen, N. I.: Integration of measurements and model simulations to characterize Eyjafjallajökull volcanic aerosols over south-eastern Italy, Atmos. Chem. Phys., 12, 10001-10013, doi:10.5194/acp-1210001-2012, 2012.

Platt, C. M. R.: Remote sounding of high cloud, Part I: Calculations of the visible and infrared optical properties from lidar and radiometer measurements. J. Appl. Meteorol., 18, 1130-1143, 1979.

Porter, J. N., Lienert, B., and Sharma, S. K.: Using horizontal and slant lidar measurements to obtain calibrated aerosol scattering coefficients from a coastal lidar in Hawaii, J. Atmos. Ocean. Technol., 17, 1445-1454, 2000.

Robinson, C. E. and McKay, D. J.: A practical cloud algorithm for automatic weather stations, Instruments and Observing Report No. 35, Fourth World Meteorological Organisation Technical Conference on Instruments and Methods of Observation, WMO/TD 303 (World Meteorological Organisation), Geneva, 1989.

Rothman, L. S., Jacquemart, D., Barbe, A., Chris Benner, D., Birk, M., Brown, L., Carleer, M., Chackerian Jr, C., Chance, K., Coudert, L., Dana, V., Devi, V. M., Flaud, J.-M., Gamache, R. R., Goldman, A., Hartmann, J. M., Jucks, K. W., Maki, A. G., Mandin, J.-Y., Massie, S. T., Orphal, J., Perrin, A., Rinsland, C. P., Smith, M. A. H., Tennyson, J., Tolchenov, R. N., Toth, R. A., Vander Auwera, J., Varanasi, P., and Wagner, G.: The HITRAN 2004 molecular spectroscopic database, J. Quant. Spectrosc. Radiat. Transfer, 96, 139-204, doi:10.1016/j.jqsrt.2004.10.008, 2005.

Schumann, U., Weinzierl, B., Reitebuch, O., Schlager, H., Minikin, A., Forster, C., Baumann, R., Sailer, T., Graf, K., Mannstein, H., Voigt, C., Rahm, S., Simmet, R., Scheibe, M., Lichtenstern, M., Stock, P., Rüba, H., Schäuble, D., Tafferner, A., Rautenhaus, M., Gerz, T., Ziereis, H., Krautstrunk, M., Mallaun, C., Gayet, J.F., Lieke, K., Kandler, K., Ebert, M., Weinbruch, S., Stohl, A., Gasteiger, J., Groß, S., Freudenthaler, V., Wiegner, M., Ansmann, A., Tesche, M., Olafsson, H., and Sturm, K.: Airborne observations of the Eyjafjalla volcano ash cloud over Europe during air space closure in April and May 2010, Atmos. Chem. Phys., 11, 2245-2279, doi:10.5194/acp-11-2245-2011, 2011.

Shipley, S. T., Tracy, D. H., Eloranta, E. W., Trauger, J. T., Sroga, J. T., Roesler, F. L., and Weinman, J. A.: A High Spectral Resolution Lidar to measure optical scattering properties of atmospheric aersols, Part I: Intrumentation and theory, Appl. Optics, 23, 3716-3724, 1983.

Stachlewska, I. S., Markowicz, K. M., and Piadlowski, M.: On forward Klett's inversion of ceilometer signals, in: Proc. 25th ILRC International Laser Radar Conference, 5-9 July 2010, St. Petersburg, Russia, 1154-1157, 2010.

Sundström, A. M., Nousiainen, T., and Petäjä, T.: On the quantitative low-level aerosol measurements using ceilometertype lidar, J. Atmos. Ocean. Technol., 26, 2340-2352, doi:10.1175/2009JTECHA1252.1, 2009.

Svensson, G., Holtslag, A. A. M., Kumar, V., Mauritsen, T., Steeneveld, G. J., Angevine, W. M., Bazile, E., Beljaars, A., de Bruijn, E. I. F., Cheng, A., Conangla, L., Cuxart, J., Ek, M., Falk, M. J., Freedman, F., Kitagawa, H., Larson, V. E., Lock, A., Mailhot, J., Masson, V., Park, S., Pleim, J., Söderberg, S., Weng, W., and Zampieri, M.: Evaluation of the diurnal cycle in the atmospheric boundary layer over land as represented by a variety of single-column models: the second GABLS experiment, Bound.-Lay. Meteorol., 140, 177-206, doi:10.1007/s10546-0119611-7, 2011.

Thorsteinsson, T., Jóhannsson, T., Stohl, A., and Kristiansen, N. I.: High levels of particulate matter in Iceland due to direct ash emissions by the Eyjafjallajökull eruption and resus- 
pension of deposited ash, J. Geophys. Res., 117, B00C05, doi:10.1029/2011JB008756, 2012.

Wiegner, M.: Potential of ceilometers for aerosol remote sensing: a preliminary assessment, in: Proc. 25th International Laser Radar Conference, 5-9 July 2010, St. Petersburg, Russia, 914917, 2010

Wiegner, M. and Geiß, A.: Aerosol profiling with the Jenoptik ceilometer CHM15kx, Atmos. Meas. Tech., 5, 1953-1964, doi:10.5194/amt-5-1953-2012, 2012.
Wiegner, M., Groß, S., Freudenthaler, V., Schnell, F., and Gasteiger, J.: The May/June 2008 Saharan dust event over Munich: intensive aerosol parameters from lidar measurements, J. Geophys. Res., Vol. 116, D23213, doi:10.1029/2011JD016619, 2011.

Wiegner, M., Gasteiger, J., Groß, S., Schnell, F., Freudenthaler, V., and Forkel, R.: Characterization of the Eyjafjallajökull ashplume: potential of lidar remote sensing, Phys. Chem. Earth, 4546, 79-86, doi:10.1016/j.pce.2011.01.006, 2012. 